\title{
Maria and Andrea: Comparing Positive and Negative Outcome Cases in an Online, Clinician-Guided, Self-Help Intervention for Panic Disorder
}

\author{
AMALIA M CIUCA, ${ }^{\mathrm{a}, \mathrm{b}, \mathrm{c}}$ THOMAS BERGER, ${ }^{\mathrm{b}}$ \& MIRCEA MICLEA ${ }^{\mathrm{a}}$ \\ ${ }^{\mathrm{a}}$ Department of Psychology, Babeş-Bolyai University, Cluj-Napoca, Romania \\ b Department of Clinical Psychology and Psychotherapy, University of Bern, Bern, Switzerland \\ ${ }^{\mathrm{C}}$ Correspondence regarding this article should be sent to Amalia M Ciuca, Department of Psychology, Babeş-Bolyai \\ University, Republicii street no. 37, 400015, Cluj-Napoca, Romania \\ Email: amaliaciuca@psychology.ro \\ Author Note: This research was supported by a Scientific Exchange Programme NMS.CH Fellowship granted to the \\ first author (Sciex Fellowship 13.224 - Sciex-N-9, contract no. 37435). \\ Editor Note: The authors were provided the opportunity to respond to the commentaries in this issue about their case \\ studies. However, the authors responded that they did not feel a need to do this since they agreed with almost all the \\ discussion points raised by the commentaries.
}

\begin{abstract}
Hundreds of clinical trials offer strong efficacy evidence that Internet-Based CognitiveBehavioral Treatment (ICBT) interventions can contribute substantially to reducing the gap between mental health care needs and service use by providing better access to quality treatments. However, in order to use these interventions more efficiently, we need to find the best ways to tailor the interventions according to individual client characteristics, such as severity of symptoms, comorbidity problems, personality traits, life context, and position on the stage-of-change continuum. In line with this, this article documents how the individual process of psychological treatment unfolds during a specific IBCT program for Panic Disorder, called "PAXonline," with therapist guidance via Skype. The challenges and progress made by the two clients-a positive-outcome client named "Maria,” and a negative-outcome client named "Andrea"-are presented using the particular mixed-methods model approach proposed by Fishman (2008; 2017), called the "Individual-Case-Comparison" (ICC) method. Contrasting Maria and Andrea's case studies explores the role that individual client characteristics can play in determining outcome in ICBT treatment.
\end{abstract}

Key Words: Panic Disorder; Internet-Based CBT Treatment (ICBT); cognitive-behavioral treatment; real-time audio-video guidance; clinical case studies; case studies

\section{CASE CONTEXT AND METHOD}

\section{Treating Mental Disorders Online}

Mental health disorders affect hundreds of millions of lives worldwide, and failing to address them properly imposes a major burden on society and leads to substantial socioeconomic losses. Even though the cumulative lifetime prevalence for all mental health 
disorders is above 46\% (Kessler et al., 2005), only a small percentage of the affected individuals reach out and receive treatment for their problems, while $60 \%$ of those in need receive no treatment at all (Wang et al., 2005).

The last decade brought on new viable solutions aimed at increasing access to quality treatment, and despite having different formats and ways of delivery, their main function could briefly be described as the provision of psychotherapy services using computers, mobile devices, and Internet technology (Ciuca, Berger, Crisan, \& Miclea, 2016). There are at least four types of such models. The first type is an Internet-based intervention, which is primarily client-guided and executed by means of a prescriptive online program through a website (Barak, Klein, \& Proudfoot, 2009). The second type is an Internet-based, manualized intervention that is specifically created to serve a psychotherapeutic purpose by implementing the principles and methods of a bona fide psychotherapy — such as cognitive-behavioral therapy, problem-focused therapy, psychodynamic therapy, and experiential therapy-and involves the client in a range of psychotherapeutic activities by using interactive, Internet-based components (Miclea, Miclea, Ciuca, \& Budau, 2010). The third type of intervention is E-counseling or online therapy, which does not involve a prepared self-help material or an Internet-based program, but rather involves traditional therapy that is delivered over the Internet either through synchronous communication (e.g. via Skype or another similar application like chat), or through asynchronous communication, e.g., by exchanging emails (G. Andersson, 2015). A fourth type is blended therapy, in which a computer, mobile device or tablet is used in face-to-face sessions or between sessions to access additional therapeutic resources (Krieger et al., 2014).

Further, Internet-based interventions can be offered with or without additional support from a therapist or counselor. Web-based interventions without additional support are "self-guided" or "unguided” programs, whereas those with additional support are "guided” or "supported" programs. The support provided in guided internet treatments can vary greatly, from a few minutes to one hour per client each week (G. Andersson, 2015). Although some Internet programs addressing anxiety disorders, mood disorders, or other psychiatric conditions have been tested with strong positive results (Hedman, Ljotsson, \& Lindefors, 2012; Mewton, Smith, Rossouw, \& Andrews, 2014; D. Richards \& Richardson, 2012) and have even been integrated into regular health care (G. Andersson \& Titov, 2014), there are countries where validated Internet-based interventions are yet to be developed or tested.

\section{Online Treatment for Panic Disorder and Other Anxiety Disorders in Romania}

Anxiety disorders, the most prevalent type of mental disorder (Kessler et al., 2005), have proved to be one of the most approachable and treatable disorders through web-based treatments (E. Andersson et al., 2012; Berger, Boettcher, \& Caspar, 2014; Boettcher, Carlbring, Renneberg, \& Berger, 2013; Ivarsson et al., 2014; Titov, Andrews, Johnston, Robinson, \& Spence, 2010). Clinician-guided programs (that is, Internet-based treatment plus assistance from a therapist, offered over an encrypted e-mail system) have been shown in some studies to have equivalent overall effects compared with traditional, face-to-face treatment therapy (G. Andersson, Cuijpers, Carlbring, Riper, \& Hedman, 2014). 
Motivated by the promising positive impact of cognitive-behavioral therapy delivered via the internet (ICBT), we sought to develop an Internet-based solution to overcome the low accessibility of psychotherapeutic services in Romania, where $76.4 \%$ of those in need receive no treatment at all (Florescu et al., 2009). Our efforts led to the development of "PAXonline," a professional ICBT platform for the prevention and treatment of anxiety disorders. (For more on this development, see Chapter 3 in Ciuca, 2016). The platform allows patients to follow multimedia intervention modules clustered in therapeutic programs addressing several types of anxiety disorders. The patient can use these modules either alone or with therapist assistance provided via Skype.

In order to test the efficacy of the PAXonline program for panic disorder ("PAXPD”), a randomized controlled trial (RCT) was conducted (Ciuca et al., 2016). Due to the fact that (a) there are still divergent results regarding the role of therapist guidance in ICBT (Baumeister, Reichler, Munzinger, \& Lin, 2014; Berger, Caspar, et al., 2011; Berger, Hammerli, Gubser, Andersson, \& Caspar, 2011; Botella et al., 2010; Furmark et al., 2009), and (b) the efficacy of Skype-based (or equivalent) therapy supportive sessions in ICBT had not been previously investigated, a central focus of our study was to test the enhancing impact of therapeutic guidance offered via Skype, as compared with a condition of the PAXPD without therapeutic guidance and with a waiting list condition. The results of the RCT study revealed that while both the non-guided and Skype-guided condition were statistically superior in outcome to a waitinglist condition, the Skype-guided condition had superior outcomes to the non-guided condition by a variety of indicators, including at six-months follow-up (Ciuca, Berger, Crisan, and Miclea, 2017, under review).

\section{The Role of Qualitative Analysis and the Mixed-Methods Model}

In addition to answering important questions regarding the efficacy of different forms of ICBT through quantitative analysis, we decided to also undertake a qualitative approach to our RCT. There are hundreds of clinical trials in Internet-based research, but we know little about individual paths in therapy, about how patients use these kinds of interventions, and their experiences during the process of therapy. Despite the large number of clinical trials examining the efficacy and effectiveness of web-based interventions, qualitative approaches are still scarce in this field (Rozental, Forsström, Tangen, \& Carlbring, 2015). Quantitative group data are of value in describing general relationships across groups of subjects involving a few variables, while qualitative case data are of value in thickly described processes within individual cases, processes that can vary in complex patterns between and among individual patients (Fishman, 2013).

Most of the former qualitative studies used interviews, written open-ended questions, and thematic analysis (Beattie, Shaw, Kaur, \& Kessler, 2009; Bendelin et al., 2011; Donkin \& Glozier, 2012; Halmetoja, Malmquist, Carlbring, \& Andersson; Ly et al., 2015). Our approach relies on the paradigm described by Fishman (2008, 2011, 2013) in his "Individual CaseComparison" (ICC) model, which he later on further developed and titled the "Case Studies Within Psychotherapy Trials” model (Fishman, Messer, Edwards, \& Dattlio, 2017). The "mixed methods" model in psychotherapy research was proposed by Dattilio, Edwards, and Fishman 
(2010) in order to bridge the epistemological and pragmatic differences between practitioners and group researchers, maximizing the advantages of quantitative and qualitative research. It is worth mentioning that the "Evidence-Based Practice in Psychology" model supported by the American Psychological Association (2006) incorporates a mixed methods model, viewing the best therapy practice as an integration of the results of quantitative, group-based treatment research with case-based, contextualized clinical expertise, and the idiographic tailoring of therapy to patient values and preferences (Fishman, 2011).

The "Individual-Case-Comparison" (ICC) method proposed by Fishman in 2008 is a particular mixed-methods model approach. It states that

systematic qualitative and quantitative case studies of a sample of poor outcome clients in comparison to good outcome clients—all taken from the successful RCT condition—provide an opportunity to investigate holistically, precisely, and in detail the individual and interactive roles of a variety of factors that affect the outcome for each specific client (Fishman, 2011, p. 243).

Individual time course data are very important; they can help us move from the question of whether change occurs toward an understanding of how change occurs (Barkham, Stiles, \& Shapiro, 1993). By using the ICC method we can add to the limited knowledge that exists about mechanisms of change in ICBT (G. Andersson, 2015). Unfortunately, case study reports are scarce in ICBT and most of the time they are only used for preliminary tests. A case series study involving five Singaporean Chinese children provided preliminary support for a culturally appropriate, ICBT program combined with treatment-as-usual for treating selective mutism (Ooi, Raja, Sung, Fung, \& Koh, 2012). In a recent case study report, an OCD patient, who had never sought treatment before, was presented using an ICBT intervention with therapist phone support (Patel, 2015). The client found the treatment delivery approach acceptable and clinical benefit was reported.

Another group of researchers (Spence et al., 2008) used two case studies to illustrate the practical and technical aspects of implementing the intervention and demonstrated the feasibility of achieving successful outcomes using IBCT for child and adolescent anxiety. Finally, a recent case study reported the course and outcomes of using a stand-alone eHealth intervention for adjustment disorder (Maercker, Bachem, Lorenz, Moser, \& Berger, 2015). However, to the best of our knowledge, the ICC method has never been applied for illustrating the use of Internet interventions. There is a need for more systematic case studies detailing the clinical process of treating patients using ICBT programs in order to provide a "bottom-up" understanding of this type of intervention.

The main purpose of this study is to document how the individual process of psychological treatment unfolds during an ICBT program for panic disorder with therapist guidance via Skype. We also hope to identify the candidate predictors, that is, moderators and/or mediators of treatment outcome that could be later tested in future studies. 


\section{Treatment Context}

The two clients_-"Maria" and "Andrea"-presented in this article were drawn from our randomized controlled trial (RCT), which was designed to evaluate the efficacy of an ICBT program for panic disorder. In this RCT, the participants, 111 Romanian adults meeting diagnostic criteria for panic disorder according to a clinical diagnostic interview conducted via Skype or telephone, were randomly assigned to one of the following three conditions: (a) independent use of an ICBT self-help program, called "PAXonline"; (b) the same self-help treatment with regular therapist support via Skype; or (c) a waiting-list control group. More details about the trial can be found in Ciuca, Berger, Crişan, and Miclea (2016) and in Ciuca, Berger, Crisan, and Miclea (under review).

In the RCT, both Maria and Andrea were participants in the experimental condition involving the receipt of PAXPD with the regular support of a therapist via secured Skype. They were chosen as representative of contrasting outcomes, with Maria attaining a very positive outcome, and Andrea, a more negative outcome. Both cases are typical for their experimental condition of the RCT, being college-educated women who were clinically diagnosed both with panic and with comorbid symptoms of anxiety and depression.

In order to enhance the rigor of our case studies, we used the following methodological strategies: (a) we audio-recorded the therapy sessions so that they could be studied systematically and be made available to independent evaluators afterwards; (b) we collected standardized quantitative data from self-report questionnaires as well as details about the time spent in the Internet platform and how the treatment was used; and (c) we had an independent clinical evaluator assess the client before and after therapy.

\section{Confidentiality}

Both clients' identities have been disguised to protect their confidentiality. They provided written informed consent for participating in the RCT and for anonymous use of their data to illustrate the intervention.

\section{THE CLIENTS}

Maria was a 21-year-old college student, studying away from her family. Her nuclear family included just her mother and a younger sister; her father had left before she was born and he never recognized her as his daughter. When Maria started the intervention, she had a diagnosis of severe panic disorder and agoraphobia, and she needed to be in the company of someone else even when staying at home. She also had comorbid depressive and generalized anxiety disorder symptoms.

Andrea was a 38-year-old woman, working as an assistant manager in an office, though she had a diploma in literature. She was still living with her mother; her father had passed away 18 months before she started treatment. She had a diagnosis of panic disorder, which prevented her from leaving the house without a trustworthy person. She had a medical condition, Cervical Spondylosis, which was aggravating some of the panic symptoms, especially dizziness and headaches. She had a previous major depressive episode 14 years before the current treatment 
started and a mixed subclinical anxiety-and-depression episode after losing her father. When she started the intervention program for panic disorder, she also had depressive, obsessivecompulsive, and generalized anxiety symptoms, but did not formally fulfill the diagnostic criteria for any of these latter three disorders.

\section{GUIDING CONCEPTION: ICBT FOR PANIC DISORDER}

Cognitive and behavioral theories generally conceptualize Panic Disorder as an acquired fear of somatic sensations of autonomic arousal (Craske \& Barlow, 2007). The CBT model is based on the adaptive nature of fears in primitive environments (Leahy \& Holland, 2000). The "flight, fight, or freeze” response was and still is adaptive in certain genuinely dangerous situations, but when it is experienced as panic in everyday situations, it is no longer adaptive. The CBT model used in our treatment program distinguishes among general vulnerability factors like neuroticism, key specific factors (i.e., cognitive interpretation of somatic sensations), and maintenance factors (like learned avoidance behaviors); and the model explains how an initial panic attack may occur and how a Panic Disorder may develop.

According to the CBT model, a first panic attack can occur when, due to any given reason, the individual experiences an increase in physiological arousal (such as dizziness, heart palpitations, hyperventilation, and sweating), and then negatively interprets these changes as being threatening ("something it's wrong") and focuses excessively on them. This hypervigilance increases the arousal, and thus the person is more strongly convinced of being in danger, so a false alarm is set off and a full panic attack develops. A lot of people have panic attacks, but not everyone develops a Panic Disorder. Anticipatory anxiety, hypervigilance toward somatic symptoms, and excessive safety and avoidance behaviors are the factors that appear after an initial panic attack and increase the likelihood of developing a Panic Disorder (Leahy \& Holland, 2000).

A multicomponent CBT intervention includes techniques (a) to lower physiological arousal via relaxation training; (b) to reduce cognitive misinterpretation via cognitive restructuring; (c) to develop coping skills like breathing retraining; (d) to reduce fear toward somatic sensations via interoceptive exposure; and (e) to reduce maladaptive avoidance behaviors via exposure to feared stimuli. Research studies have shown that cognitive-behavioral treatments for Panic Disorder and Agoraphobia are very effective (75-90\% efficacy), and that there are long-term therapeutic effects (Leahy \& Holland, 2000). In vivo exposure is the technique that seems to provide the greatest benefit, and the inclusion of homework during the intervention can improve the effectiveness of treatments (Sanchez-Meca, Rosa-Alcazar, Marin-Martinez, \& GomezConesa, 2010).

Internet cognitive behavioral treatment (ICBT) programs for panic disorder (PD) and agoraphobia have been developed in the last 15 years, and there are several empirical studies supporting their efficacy and effectiveness (Bergstrom et al., 2010; Carlbring et al., 2006; Carlbring et al., 2005; Farvolden, Denisoff, Selby, Bagby, \& Rudy, 2005; Kiropoulos et al., 2008; Klein, Richards, \& Austin, 2006; Nordgreen et al., 2010; J. C. Richards, Klein, \& Austin, 2006; Ruwaard, Broeksteeg, Schrieken, Emmelkamp, \& Lange, 2010; Shandley et al., 2008; 
A.M. Ciuca, T. Berger, \& M. Miclea

Pragmatic Case Studies in Psychotherapy, http://pcsp.libraries.rutgers.edu/

Volume 13, Module 3, Article 1, pp. 173-216, 11-11-17 [copyright by authors]

Wims, Titov, Andrews, \& Choi, 2010). Hedman et al. (2013) found that such programs have a mean within-group effect size of 1.32 , with a range of 0.79 and 1.97

\section{Treatment Description}

\section{The PAXonline Program for Panic Disorder (PAXPD)}

The PAXonline program for Panic Disorder (PAXPD) is a 12-week, Internet-based treatment that consists of cognitive-behavioral therapy modules, delivered with or without assistance from a therapist. It was developed de novo by the authors, based on empirically validated cognitive-behavioral models of anxiety disorders (Andrews, 2003; Clark \& Beck, 2011; Leahy \& Holland, 2000), and the program is currently the only available psychological treatment of this kind in Romania. Our main target was to create a safe and secure environment with the necessary resources in which the patient feels empowered and ready to get involved in his or her internal process of change.

PAXPD contains 16 modules addressing important cognitive-behavioral psychotherapy elements such as: psychoeducation; techniques for decreasing neurophysiologic hyperarousal; cognitive restructuring; exposure exercises; positive emotions training; problem-solving training; behavioral activation; cognitive restructuring exercises to reduce symptoms of depression; and relapse prevention. The modules follow a specific structure and the content is offered based on existing principles from the learning and cognitive sciences, in order (a) to enhance user experiences; (b) to support the development of skills and behavior and goal monitoring; and (c) to track progress (Miclea, Miclea, \& Ciuca, 2008).

Each PAXPD module contains the following sequences: mood checking; setting objectives; presenting content; a summary; checking the level of understanding through several multiple-choice questions; homework; and reward. The information is presented in a multimedia format including text, graphics, short movies, and animations. Case studies are presented in order to facilitate understanding and offer a model for putting the recommended exercises into practice (i.e., vicarious learning). Each module can be completed in 15-40 minutes, and the participants are provided with a recommended timetable (one or two modules per week, depending on the complexity of the content and the homework assignments).

Table 1 presents a chart sequentially summarizing the 16 modules.

\section{Guidance Sessions}

In guided online programs, asynchronous communication (via email or text message) is most commonly used and, on average, patient guidance does not take more than 10 minutes per week (G. Andersson, 2015). In our study design, we provide guidance through synchronous (real time) audio-video communication (i.e., video chat programs such as Skype). We consider that this type of communication closely matches face-to-face therapy and enables access to important face-to-face cues. Through real-time interactions, therapists may be able to offer more immediate, individually tailored feedback and support according to each patient's personal needs 
(Abbott, Klein, \& Ciechomski, 2008), and a better therapeutic alliance may develop (Simpson \& Reid, 2014).

Participants belonging to the PAXPD treatment group with assistance have regular 15-30 minute Skype sessions with their psychotherapist (the length depends on the complexity of the modules and the needs of each patient). During these secured Skype sessions, the psychotherapist checks if the participant completed and understood each module, answers questions, and helps the participant carry out the recommended exercises. The main purpose of each Skype session is to make sure that the patient has everything needed in order to put the recommended exercises into practice on a regular basis. The sessions are scheduled via an encrypted asynchronous communication system available on the treatment platform, for both the psychotherapist and the client. The participants are also allowed to use this system between two Skype sessions if they need further clarifications from their therapists. In total, a maximum of 10 Skype sessions were available for each participant.

\section{ASSESSMENT OF THE CLIENTS' PROBLEMS, GOALS, STRENGTHS, AND HISTORY}

\section{Standardized Assessment Measures in the Randomized Control Trial That Were Employed In Assessing the Two Cases}

Maria and Andrea went through the assessment process employed with all the clients in the RCT (Ciuca et al., 2016). The inclusion and exclusion criteria for being accepted into the RCT were as follows:

Participants are included in the study if the following conditions are met: (1) their symptomatology fulfills the diagnostic criteria for panic disorder according to DSMIV-TR (APA, 2000); (2) their age is within the range of 18-65 years; (3) they have access to a computer with internet connection; (4) they are native Romanian speakers; and (5) they provide written informed consent.

Participants are excluded if any of the following criteria is met: (1) they are currently enrolled in a different psychotherapeutic program or have received psychotherapy in the previous 3 months; (2) they present severe comorbidities, other than a different anxiety disorder or mild depression (e.g. bipolar disorders, psychotic disorders, substance abuse); (3) they suffer from mental retardation; (4) their symptoms are aggravated by a severe medical problem (e.g. ventricular tachycardia, heart attack, stroke, pulmonary fibrosis, hyperthyroidism, epilepsy); (5) they present suicidal ideation or behaviors.

Medication use is permitted, but only if the dosage has been constant in the previous month and the same dosage must remain constant during the trial. Benzodiazepines are not allowed, according to existing recommendations [from the research literature] . ... All eligible participants must fill out and return a detailed informed consent form before starting the trial (Ciuca et al., 2016, p. 5).

The primary and secondary symptom measures are listed below (for more details, see Ciuca et al., 2016). All were collected at baseline (pre-treatment), during treatment (6 weeks 
A.M. Ciuca, T. Berger, \& M. Miclea

Pragmatic Case Studies in Psychotherapy, http://pcsp.libraries.rutgers.edu/

Volume 13, Module 3, Article 1, pp. 173-216, 11-11-17 [copyright by authors]

after the intervention started), at post-treatment (12 weeks after baseline) and follow-up (1, 3, 6, and 12 months after the intervention ended.) All self-report measures were administered online.

\section{Primary Outcome Measures}

- $\quad$ Psychiatric Diagnostic Screening Questionnaire (PDSQ; Ciuca et al., 2011; Zimmerman \& Mattia, 2001). This involves a self-report screening scale, followed by a semi-structured interview delivered by a clinician through Skype or by phone.

- $\quad$ Panic Disorder Severity Scale-Self Report (PDSS-SR; Houck, Spiegel, Shear, \& Rucci, 2002), a self-report scale measuring severity of Panic Disorder.

\section{$\underline{\text { Secondary Outcome Measures }}$}

- $\quad$ Work and Social Adjustment Scale (WSAS; Mundt, Marks, Shear, \& Greist, 2002), a 5item, straightforward, reliable and valid measure of self-reported functional impairment . We chose this measure as a self-report measure of functional impairment produced by anxiety symptoms.

- $\quad$ Patient Health Questionnaire (PHQ-9; Kroenke, Spitzer, Williams, \& Lowe, 2010), a widely used measure of depression.

- $\quad$ Panic Attack Cognition Questionnaire (PACQ; Clum, Broyles, Borden, \& Watkins, 1990),_a 25-item scale assessing the extent to which catastrophic cognitions dominate a subject's thoughts before, during, or after panic attacks.

- Body Vigilance Scale (BVS; Chambless, Caputo, Bright, \& Gallagher, 1984), which measures the degree of attentional focus on and perceived sensitivity towards changes in bodily sensations, and the amount of time spent scanning for bodily sensations.

- $\quad$ Agoraphobic Cognitive Questionnaire (ACQ; Chambless, Caputo, Bright, \& Gallagher, 1984), a 14-item self- report questionnaire, which assesses the frequency of frightening or maladaptive thoughts about the consequences of panic and anxiety. The measure has two subscales: a Physical Concerns Scale, involving autonomic nervous system symptoms, and a Loss of Control Scale, involving catastrophic cognitions, such as fear of dying and fear of losing control or going crazy.

- $\quad$ Body Sensations Questionnaire (BSQ; Chambless, Caputo, Bright, \& Gallagher, 1984), which measures the concept of "fear of anxiety," that is, the degree to which sensations associated with autonomic arousal (e.g., "feeling short of breath" and "heart palpitations”) are experienced as frightening.

- Global Assessment of Functioning Scale (GAF Scale); American Psychiatric Association, 1994). This is a numeric scale used by mental health clinicians and physicians to rate subjectively the psychological, social, and occupational functioning of an individual on a hypothetical continuum of mental health vs. illness, ranging from 1 to 100 on the social, 
occupational, and psychological functioning of an individual, e.g., how well the individual is meeting various problems-in-living. Scores range from 100 (extremely high functioning) to 1 (severely impaired).

- $\quad$ Self-Report Level of Anxiety. This was a simple scale constructed by the authors measuring self-reported anxiety in the present time, ranging from 0 (no anxiety0 to 10 (maximum anxiety).

\section{Assessment of Maria}

\section{$\underline{\text { Assessment on Standardized Scales }}$}

On the Psychiatric Diagnostic Screening Questionnaire (PDSQ), Maria’s self-report presented high scores for depression, obsessive-compulsive disorder (OCD), somatization and agoraphobia; and maximum scores for panic disorder, generalized anxiety disorder (GAD), and hypochondria. The clinical interview confirmed the presence of all of these symptoms, particularly the depressive symptoms and the presence of trait anxiety.

Maria's scores on the standardized, self-report measures at pre-treatment can be seen in Table 2. Consistent with her clinical diagnoses, Maria’s Panic Disorder Severity Scale (PDSS$\mathrm{SR}$ ) score indicated a severe panic disorder with agoraphobia

On the secondary outcome measures, Maria's overall functioning received a GAF Scale rating of 50, reflecting the presence of serious symptoms or serious impairments in social, vocational, or school functioning. Maria also indicated a significant impairment in functioning on the WSAS scale and moderate levels of depressive symptoms on the PHQ-9. She also presented a high level of catastrophic cognitions, high body vigilance, high fear of losing control over her body, intense preoccupation with physical sensations, and intense fear of bodily sensations.

\section{Problem History}

Maria was a student in a large city and lived with roommates in a rented flat. She was involved in a long-term relationship, and her boyfriend was very supportive. Maria described herself as being an anxious person her entire life. She was raised by a single parent, her mother, whom she described as being "neurotic and extremely sensitive" and who used to take Xanax for many years. Maria had her first panic attack eight months before the treatment started, after her mother had given her half of a Xanax pill to help her with some palpitations and restlessness symptoms. She felt worse and started to think that the pills were harmful and something bad would happen. The panic attack she experienced was so intense that she ended up in the emergency room. Afterwards, she had 2 to 3 panic attacks per day, which motivated her to undergo multiple medical examinations. As the results indicated no somatic problems, she was referred to a psychiatrist.

The psychiatrist prescribed her Xanax and Paroxetine as treatment, but she refused to take the medication. She tried to cope on her own, but the panic attacks became worse. She gradually 
A.M. Ciuca, T. Berger, \& M. Miclea

Pragmatic Case Studies in Psychotherapy, http://pcsp.libraries.rutgers.edu/

Volume 13, Module 3, Article 1, pp. 173-216, 11-11-17 [copyright by authors]

started to avoid going out alone, staying home alone (she associated her home with the first panic attack) and gave up physical exercise, which she used to practice before.

When she entered treatment, she was still convinced that something was physically wrong with her and that she might die of a heart attack or a stroke. The main symptoms during her panic attacks were palpitations, heat and pressure in the chest, dizziness, breathing problems, a lump in her throat, the left side of her body getting numb, and thoughts that she would die.

Maria said that she was a sensitive and shy girl her entire life, but that it did not stop her from having a pleasant childhood and adolescence.

Maria said that her mother and her grandparents, who raised her until she was 7 years old, were all very sensitive and shy people. Regarding her biological father, she said: "I don't have a father. He never recognized me as his daughter. I know who he is, but he is of no importance to me."

When she was 12 years old, her mother remarried and she reported having a good relationship with her stepfather. She considered that her life was on a good track when the panic attacks began, and aside from normal worries typical for any student, such as, "Am I going to find a good job after I graduate?”, she was satisfied with her choices.

During summers, she used to work as a waitress in order to help her mother with the bills, but also to have some pocket money. The job was quite exhausting, and she worked long hours late into the night. The first panic attack occurred after a busy week at work. Before starting treatment, the frequency of her panic attacks was 3 to 4 per week, occurring in different places and situations (e.g. at home, when she was alone, in the train, on the street, or at the university).

\section{Assessment of Andrea}

\section{$\underline{\text { Assessment on Standardized Scales }}$}

On the Psychiatric Diagnostic Screening Questionnaire (PDSQ), Andrea's self-report presented high scores for depression and GAD, above cut-off scores for hypochondriasis, posttraumatic stress disorder (PTSD), somatization, and social phobia, and maximum scores for panic disorder and agoraphobia. The clinical interview confirmed the presence of most of these symptoms plus claustrophobia, but not symptoms of social phobia and PTSD.

Andrea's scores on the standardized, self-report measures at pre-treatment can be seen in Table 2. As can be seen, consistent with her clinical diagnosis, Andrea's Panic Disorder Severity Scale (PDSS-SR) score indicated a severe panic disorder with agoraphobia.

On the secondary measures, Andrea's overall functioning received a GAF rating of 45, reflecting the presence of serious symptoms or serious impairment in social, vocational, or educational functioning. Also, Andrea's scores indicated a significant impairment in functioning on the WSAS and a moderate level of depression on the PHQ-9. She also presented a high level of catastrophic cognitions, high attentional focus on interoceptive activity, high fear of losing 
control over her body, intense preoccupation with physical sensations, and intense fear of bodily sensations.

Note that overall, Maria's and Andrea's pre-treatment scores, as shown in Table 2, are strikingly similar.

\section{Problem History}

Andrea has been living her entire life with her parents, and used to have a very close relationship with her father and sister. She felt "completely abandoned” after her father died (18 months prior to beginning of treatment) and when her sister moved to another city (9 months prior to beginning of treatment). Her panic attacks started later, just 7 months before entering the treatment program, and were sometimes triggered by the cervical spondylosis from which she was chronically suffering - since this condition occasionally gave her headaches, pressure in the head, and dizziness and feelings of passing out.

Andrea offered a positive account of her childhood, with loving parents, grandparents, and good friends surrounding her. She graduated from her university with a major in literature, and after a few months she had the opportunity to work in an office as an assistant manager. She said that she never liked the job: "I'm stuck in a job in which I have never felt good, from the beginning until now," but she couldn't find the strength to change it: "I haven't been able to change it; I got used to it and ultimately it has been a safe place ...I am afraid to fail, I don't trust myself."

At the age of 24 (Andrea's current age was 38), she had a major unpleasant event, which she never disclosed in the therapy. As a result, she experienced a major depressive episode and took medication for a few weeks. Due to side effects, she gave up the medication, took some reflexology sessions, and gradually recovered.

When Andrea started the treatment, she was single and still living with her mother. She reported that during her life she had two or three long-distance relationships. One of them lasted for several years and was "virtual": they never saw each other in person. She described the relationships as being “toxic,” but she felt that she didn’t deserve anything better. She said she needed to be with someone, even if that person was an imaginary character.

Andrea was a highly educated and well-read woman, but very anxious and overwhelmed by catastrophic scenarios in her mind: “I can’t go out by myself. Something bad will happen. It will be horrible.” Her main symptoms were headaches, dizziness, weakness in the feet, perspiration, irregular breathing, and palpitations.

In the past, she used to have friends around and spend time with them, but she gradually lost contact with most of them. When she entered treatment, she was completely isolated due to the intense fear of having a panic attack in public. She also gave up a lot of other activities, like physical exercise, walks, shopping, and reading. "I can’t go out anymore just by myself. I feel that I'm completely alone and something bad will happen and nobody will help me.” Because of this lack of activity, she felt trapped in the house and thus developed depressive symptoms, 
sleeping and eating more than usual, and losing interest in many indoor activities. She summed up her life: “I'm living in a nightmare and I'm afraid that I will never be able to get out of it."

\section{CASE FORMULATION AND TREATMENT PLAN}

We first have to mention that in Internet-based therapy, no elaborate case formulations and treatment plans are usually made. The treatment is very standardized and the main treatment components are determined beforehand while creating the self-help program. In PAXPD, the tailoring of treatment is made by the therapist or through available, optional treatment modules.

Both clients were sensitive persons, had a personal vulnerability towards anxiety, and grew up with anxious role models, including Maria’s mother and grandparents as well as Andrea's father. Their first panic attacks occurred in particularly negative life situations, which activated their general vulnerability.

\section{Maria's Case Formulation}

When Maria had her first panic attack, she was exhausted by long hours of work and was troubled by the decision she had made a few days earlier to break up with her boyfriend. The vicious cycle of panic, from sensations to catastrophic cognitions to increased sensations, led to a full-blown panic attack. Due to her increased vigilance towards body sensations and anticipatory anxiety, new panic attacks appeared, and Maria was soon convinced that she was having a serious physical illness.

Maria's avoidance behaviors became more and more pervasive, so the fear response was consolidated. She gave up a lot of activities (e.g., participating in sports and shopping in crowded places). She got back together with her boyfriend and refused to be left alone. She was unable to study and was afraid to go to her university, so she failed to take her exams. Soon, she developed a learned helplessness and started to feel depressed.

\section{Andrea's Case Formulation}

Andrea had been often feeling very sad and worried about her ability to take care of herself after losing her father's and sister's support. She was going through an existential crisis and considered herself to be hopeless.

The first panic attack was triggered by her medical condition when she was having a headache and was feeling dizzy. The vicious cycle of panic, from sensations to catastrophic cognitions like, "I'm going to faint and embarrass myself in front of these people," took place in a bus stuck in traffic. Afterward, she demanded that her mother accompany her to the bus station every morning and, soon enough, started to take a cab instead of the bus. Still mourning after her father's death, Andrea increasingly limited her social activities and even gave up shopping at the local market. Her anticipatory anxiety was so intense that only the thought of going outside started to trigger intense fear reactions. 


\section{Common Treatment Goals and Strategies for Both Clients}

In the RCT, both patients were enrolled in the PAXonline Panic Disorder program and received therapist guidance via Skype from the same therapist. Treatment goals and strategies for both clients were embedded in the program modules:

- $\quad$ read the recommended modules and complete the tasks required as part of the treatment;

- understand that the fear response is a brief, intense physical reaction designed to protect us from danger and that panic attacks are just a "false alarm";

- reduce the physical symptoms of anxiety through breathing regulation, relaxation and/or physical exercises;

- identify and reduce attentional biases;

- identify, test and change catastrophic interpretations, such as: "I’m going to faint,” or "I'm having a heart attack or a stroke";

- identify and change the dysfunctional unconscious beliefs, such as: "I'm worthless. I can’t manage to do anything on my own”;

- eliminate conditioned anxiety responses and reduce fear of physiological sensations through interoceptive exposure;

- $\quad$ engage in previously avoided activities or places in order to learn that they are not dangerous;

- cultivate positive emotions; identify personal values and strengths and cultivate them;

- $\quad$ address and reduce depressive symptoms through behavioral activation; and

- develop a sense of mastery and acquire relapse prevention skills.

\section{COURSE OF TREATMENT}

\section{Maria's Course of Treatment}

Maria found out about the study accidentally one evening, after ending up in the emergency room again due to an intense panic attack. She saw a poster in the waiting room with information about the study and decided to give it a try. Talking about entering the study, she said, "When I enrolled in the study, honestly, I didn't think it would work. At that time, my problem seemed impossible to solve. I was convinced that I'd be forced to live with it my entire life. I was also feeling a little uneasy talking about my problems with a stranger, but I decided to give it a try.” 
In fact, it later became clear that Maria was very motivated at the beginning of therapy and even read more than recommended for the first sessions. She was curious and eager to find out more about her problems and how she could reduce them.

The way Maria used the treatment program (the computer modules and Skype guidance sessions) is summarized in Table 3, which shows the sequence of her working on the 17 modules listed in Table 1 in the context of her Skype Session (SS) meetings with the therapist. The specific process details of the course of therapy is presented below.

\section{$\underline{\text { Skype Session } 1}$}

The first Skype Session was a bit longer than planned and lasted for 38 minutes. Because Maria read the Introductory Module and Modules 1 and 2 recommended in the treatment plan, the session was dedicated to several issues (see Table 1 for a list of the 17 modules: the Introductory Module and Modules 1-16). These included: the history of her panic attacks, how the first panic attack occurred, normalizing her reactions, clarifying differences between normal fear and anxiety versus pathological reactions, information on the impressive success rates of cognitive-behavioral treatments in order to increase expectancies for positive outcomes, developing a case conceptualization to help her understand the origin of the problem and the means by which it was being currently maintained, the contents of the first steps of the intervention, filling in the required questionnaires, and the symptoms evaluation/ monitoring sheets.

The explanatory model was personalized using Maria’s first panic attack experience and her reaction was, "I understand everything. That's exactly what happened to me." For homework, she was asked to record the frequency of her panic attacks and to describe each one of them in detail, using a given worksheet.

\section{$\underline{\text { Skype Session } 2}$}

The second Skype Session lasted 33 minutes and mainly addressed the reduction of hyperarousal through breathing techniques, presented in Module 3. The psychotherapist explained the normal process of breathing and how hyperventilation occurs. Then Maria and the therapist together practiced two positions for abdominal breathing and the technique for reducing breathing rate, with the therapist demonstrating as a model.

Additionally, Maria’s depressive symptoms were briefly discussed, as well as the panic attack that happened earlier that day. The psychotherapist used the opportunity to remind Maria that panic attacks may still occur, but as she was learning various techniques, including breathing methods, she would be able to deal with them more effectively.

Module 6, dedicated to physical exercises, was also briefly discussed, and the therapist recommended that Maria consider playing volleyball again (she used to play three to four times per week before the panic attacks started), or at least to take short walks or to take the stairs instead of the elevator. Maria's homework was to continue recording her symptoms, to practice the breathing exercises twice a day, and to take short walks. 


\section{$\underline{\text { Skype Session } 3}$}

This was the longest Skype Session and lasted 43 minutes. The session was dedicated to inducing relaxation through autogenic training. Interestingly enough, in the third week Maria had three panic attacks and all of them occurred while she was trying to relax after having some hard days at school and conflicts with her boyfriend. There were other times when she had some unpleasant physical sensations, but managed to stop them by using the breathing technique she had previously learned. When she was asked what she thought about the autogenic training she had just read about in the module, her answer was: "It's a little bit strange, I mean, I'm afraid to try it. I'm afraid of the heart exercise. I'm afraid even when I stay relaxed in my bed and I feel and hear how my heart beats."

The psychotherapist addressed these fears and told her that if the autogenic technique would prove to be unsuitable for her, they would use an alternative one, the progressive muscle relaxation technique. The therapist briefly explained the central aspects of the autogenic training (the mechanism, the positions, the necessary instructions for doing the exercises) and then practiced together the first exercise, inducing heaviness in the right arm. As homework, Maria had to continue with breathing exercises and to practice autogenic training twice a day.

\section{$\underline{\text { Skype Session } 4}$}

The main focus of this session was the Module 7 of the treatment, "Optimizing attentional functioning." Maria recognized her problems in the Module descriptions of attentional biases: "It describes me perfectly. That's exactly what I'm doing when I have a panic attack.” The main attentional biases (increased vigilance toward body sensations, magnifying intensity of detected unpleasant sensations, and difficulty in disengaging from these sensations) were discussed and three solutions were offered: first, pay more attention to facts, not sensations; second, set your own daily agenda and try to follow it, instead of letting your anxiety tell you what to do; and third, practice focusing your attention on positive and neutral things (e.g., take a walk and pay more attention to your external environment).

A second focus of the session referred to the obstacles Maria was facing. She had a hard week with a new disturbing symptom that frightened her and triggered an intense panic attack. The new symptom was described as "a painful heat in the chest. It's like someone punches me from inside my chest,” and was experienced only when she was very upset.

Because Maria's depressive symptoms were getting worse (she even failed to take her exams), the psychotherapist explained to Maria that they would continue the work on reducing pathological anxiety, but not before addressing her comorbid depressive symptomatology. The psychotherapist recommended that Maria practice the breathing techniques, take longer walks, and do the attentional exercises, but to read the Module 15 instead of the Module 8, which would have usually followed. Module 15, "Reducing depressive symptoms associated with panicbehavioral activation," is an optional module in the generic Panic Disorder program, dedicated to overcome learned helplessness and to practice behavioral activation. 


\section{$\underline{\text { Skype Session } 5}$}

In this session, Maria reported that she managed to do all her tasks including the recommended exercises, and that she had a very good week with no panic attacks. She met her friends twice and she managed to walk home alone from the university. The therapist encouraged her and told her she needed to learn to appreciate every small step, without comparing herself to other people. They discussed the module dedicated to dealing with depressive symptoms and decided on necessary actions she should consider for improving her well-being (e.g. to make a list with activities she likes to do and plan to do some of them every day; pay more attention to positive things throughout the day and write them down every evening). Further, they reviewed her experiences with autogenic training. She reported that she had managed to relax, but that she was still terrified about her heart beats: "Since the beginning, I had an obsession with the way my heart works. When I relax, my attention focuses on my heart and I start feeling like it's not working properly, so I get scared and I'm unable keep my focus on relaxation.” The psychotherapist decided to introduce another relaxation method, the progressive muscle relaxation. She had to continue with the autogenic training exercises, but as soon as she felt that it was not working right, she had to switch to progressive muscle relaxation.

\section{$\underline{\text { Skype Session } 6}$}

This session was dedicated to Module 8, “Changing maladaptive conscious cognitions.” In the first part of the session, the previous week and homework assignments were discussed. Maria reported having a great week and that the progressive muscle relaxation was working much better for her than the autogenic training. "I like it a lot. There is nothing threatening for me." She managed to practice all the recommended exercises, including going for longer and longer walks by herself.

Unfortunately, she had another panic attack with limited symptoms a few hours before the session while she was attending a class at her university. She was very tired, it was hot in the room, and she started to think about the first panic attacks she experienced. She went outside to get some fresh air and managed to relax in 2-3 minutes by practicing the breathing technique.

The next topic of the session was the importance of catastrophic cognitions for triggering and maintaining the panic attacks. The therapist used one of her own life experiences to help Maria understand this important aspect. The restructuring technique was exemplified by using one of Maria's dysfunctional thoughts, "I’m going to have a heart attack." Maria learned how to use the restructuring worksheets and was instructed to do these exercises in writing once a day or at least once every other day. The therapist also helped her group the homework assignments so that they would not become a burden.

\section{$\underline{\text { Skype Session } 7}$}

Maria started this session by saying how great she was feeling: "Everything is great. On a scale from 0 to 10, I'm 10." The therapist encouraged her to continue with the exercises because, "Two to three weeks are not enough to make a serious change." Maria reported that she had used the cognitive restructuring technique and managed to identify and successfully challenge her four 
most important dysfunctional beliefs: "I have a serious disease," “I'm going to have a heart attack," "I'll never get out of this," and "I should give up-there's no use to continue fighting." Her main challenging, functional conclusion was, "I can beat my anxiety. I'm young; I have an entire future waiting for me.”

The main topic of this session was the cognitive restructuring of unconscious dysfunctional cognitions (see Module 9 in Table 1). Maria understood the module but found it very hard to identify her unconscious dysfunctional beliefs. After the therapist briefly summarized how these are formed mostly in early childhood and how they influence our perception, attitudes, and behaviors, Maria and the therapist worked together to try to identify Maria's unconscious dysfunctional beliefs. As homework, Maria had to continue with the cognitive restructuring of her conscious and unconscious beliefs, and to do an exercise in order to identify her values, the most important principles that were guiding her life.

\section{$\underline{\text { Skype Session } 8}$}

This session was dedicated to planning and practicing the interoceptive exposure technique (see Module 10 in Table 1). Before this subject was addressed, the therapist asked Maria about her mood and her homework assignments. She had had a good week, but the day before she had another limited-symptoms panic attack. It seems that this had been triggered by alcohol consumption (she had been avoiding alcohol since her panic attacks started) and lack of sleep.

She recognized that she still felt vulnerable when she was home alone, but that her attitude toward her panic attacks started to change: "I think I can face them now; I'm not so scared about them anymore.” During this session, she mentioned that while analyzing herself and trying to identify her unconscious dysfunctional beliefs, she realized that her first panic attacks happened just a few days after she broke up with her boyfriend. She was suffering a lot at that time and she was having doubts about her decision to break up.

Maria understood how avoidance maintained her anxiety and how the interoceptive exposure exercises were going to help her reduce the fear she felt toward her own body sensations even more. She practiced, together with her therapist, some of the exposure exercises and she was instructed to repeat them daily or at least 4 times per week.

\section{$\underline{\text { Skype Session } 9}$}

Due to the Easter vacation and because there were only two sessions available for the last month of treatment, almost 4 weeks passed between the $8^{\text {th }}$ Skype Session and the $9^{\text {th }}$. During this time period, Maria had chosen to read Module 11, “Avoidance reduction through exteroceptive exposure,” and then put the exposure exercises to external situations and/or activities into practice by herself.

In the beginning of the session, she reported that she was not doing very well. Three weeks earlier, at the beginning of the Easter vacation, while she was at home, she had had a panic attack. She was with her family at the dinner table; the atmosphere was quite tense and she started to feel palpitations. She reacted fine at first, but she got very scared because the 
palpitations continued for almost an hour, and her mother called an ambulance. This incident made her very upset, because she thought that, "All efforts were in vain; it will all start again and I have no control over this;" but fortunately she continued with the exposure exercises in the following days. The therapist helped her understand what happened and used the incident as an example for how to deal with a relapse in the future (anticipating Module 14 in Table 1). Further, the importance of cultivating positive emotions was discussed (anticipating Module 13). The therapist helped Maria find the best strategies for her and how to put them into practice regularly.

\section{Skype Session 10}

This session was dedicated to Module 14, relapse prevention. Maria was feeling insecure: "I'm a little bit scared. I will not have you here anymore, as my safety net, but I hope that I'll manage to be OK."

The therapist summarized all the techniques Maria learned during treatment and helped her develop a plan for when and how to use them in the next few months. Maria acknowledged all the progress she had made in the last weeks (for example, she now knew how to deal with anxiety symptoms, she managed to travel alone by train, she was no longer afraid to spend time alone, and she was taking long walks almost every day), but she knew that she still had a lot of work to do, especially with exposure exercises. She was still vulnerable to palpitations, and because of this, she was still avoiding intense physical exercise practiced alone. "I have understood that it's normal to have ups and downs, but I no longer fear those sensations. I'm still a little bit sensitive with my heart beats, but I'm feeling confident about solving this problem, too.” The session lasted for 21 minutes.

\section{Andrea's Course of Treatment}

When Andrea first heard about our RCT and the possibility of getting treatment online, she was extremely happy. She said that a face-to-face treatment would have been impossible at that time, due to her transportation problems and avoidance behaviors. However, she started worrying a lot about the treatment group she would be randomized to and felt "very lucky" when she found out that during her ICBT program she would benefit from supportive sessions offered via Skype.

The way Andrea used the treatment program (the modules and the Skype guidance sessions) is summarized in Table 3, which shows the sequence of her working on the 17 modules listed in Table 1 in the context of her Skype Session (SS) meetings with the therapist. The specific process details of the course of therapy are presented below.

\section{$\underline{\text { Skype Session } 1}$}

This session took 38 minutes and the discussion was focused on a variety of topics, mostly including: symptomatology normalization; understanding differences between fear and anxiety, and when they become pathological; factors involved in the development of anxiety disorders; setting appropriate expectancies; and using the Internet-based, PAXPD treatment program. 
Andrea worked with her therapist to identify her personal vulnerabilities (predispositions) and personal circumstances (past and present) that facilitated the emergence of her panic attacks. She recounted some of these factors:

I used to be so relaxed and peaceful around my father when he was alive and losing him was unbearable. All these changes... I adapt so hard to changes - there've been too many all of a sudden. I'm afraid of the unknown. I feel overwhelmed. ... I had difficulties making decisions my whole life. I always needed some kind of reassurance from my family or close friends.

As homework, Andrea was asked to record the frequency of her panic attacks and describe each one of them in detail using a given worksheet.

\section{Skype Session 2}

This session took longer. Andrea hadn't read all the recommended modules. She had skipped the first two modules of the PAXPD program and read the following three, Module 2, "Understanding what you have to do;" Module 3, "Reduce hyperactivation through breathing retraining;” and Module 4, "Reduce hyperactivation through autogenic training.”

Therefore, in order to enhance her motivation and commitment, the therapist first made a presentation of the whole treatment program, and then together with Andrea practiced the abdominal breathing and the exercise for slowing down breathing.

The session was extended for more than 15 minutes because Andrea asked many questions about what was going to happen, when she was going to start feeling better, and so forth. As homework, Andrea was asked to continue with the recording/monitoring of her symptoms and to practice the breathing exercises twice a day.

\section{$\underline{\text { Skype Session } 3}$}

This session was supposed to be dedicated to clarifying the explanatory model presented in Module 1, "Understand what's happening with you," and to continue with relaxation exercises (autogenic training technique). All of these goals were met, but again the session extended because Andrea talked about her emotions and her avoidance attitude toward almost everything.

The therapist used some examples and metaphors to help Andrea understand that she needed to stop the avoidance behaviors and gradually start dealing directly with her problems. Even when the autogenic training was presented, Andrea was concerned with the danger of a certain body posture: “Isn’t this position dangerous? Doesn't all your blood go to your head?”

Module 4 contains a video where the autogenic training is presented and practiced with a patient, so that the user has all the information necessary and a model of how to conduct the exercises. Still, the therapist wanted to practice the first exercise of the autogenic training with Andrea, gradually inducing heaviness in the dominant arm, so that she could have direct guidance and feedback on the experience. 
A.M. Ciuca, T. Berger, \& M. Miclea

Pragmatic Case Studies in Psychotherapy, http://pcsp.libraries.rutgers.edu/

Volume 13, Module 3, Article 1, pp. 173-216, 11-11-17 [copyright by authors]

\section{$\underline{\text { Skype Session } 4}$}

This session started with a discussion about homework assignments. Andrea was extremely stressed because she hadn't managed to practice all her exercises, and started to complain about herself and her slow pace: "I'm getting lost in details. I can’t manage to do things as I should. I've made a mess of all these exercises."

As an answer to this, her therapist outlined a brief time-management technique and told her a short therapeutic story to help her understand that having a very critical attitude toward oneself is detrimental. A few more minutes were spent on technical issues: how to download the personal portfolio to her computer, and how to upload her homework sheets.

Andrea tried to skip some steps in Autogenic Training - a detrimental decision — and the heart exercise from Autogenic Training frightened her. The therapist explained to her again why she needed to consider each exercise and practice it for a week before adding a new one.

As a way to improve her low mood, the therapist recommended that she pay more attention to positive things throughout the day and write them down every evening. According to the recommended pathway, the fourth session should have been dedicated to Module 7, "Optimizing attentional functioning," but since Andrea hadn't read it, the therapist used the last part of the session to consolidate everything Andrea had done so far.

\section{$\underline{\text { Skype Session } 5}$}

Two weeks passed between the fourth and the fifth session, so the therapist focused on two topics in the fifth session. First, the therapist addressed attentional biases by modeling two exercises that Andrea was instructed to practice daily for the next few weeks. Next, the focus was set on cognitive restructuring of conscious automatic thoughts and catastrophic cognitions, which are considered to be an important element in the cycle of developing a new panic attack.

Andrea said that she had read the recommended Module 8, "Changing maladaptive conscious cognitions." However, she started complaining about the fact that everything was too much for her: “I felt overwhelmed. It's too much for me. I couldn’t do it if I wouldn't have assistance. I wanted to give up a few times. There is too much information, too many exercises.”

In response, before discussing the cognitive strategies, the therapist once more addressed Andrea's unrealistic expectations, her strong need for control, and her perfectionism. The therapist used the comparison "conquering your Everest” in order to explain the need for the intense preparation, patience, and hard work that is necessary for reducing anxiety problems.

The therapist reintroduced the technique presented in Module 8, "Changing maladaptive conscious cognitions," and helped Andrea identify the most important thoughts that made her anxious. She then showed Andrea how to challenge each thought and find a more appropriate and functional one instead. Thus, the therapist modeled the way to identify and challenge dysfunctional cognitions. 
Once again, Andrea's tendency to exaggerate the consequences of certain situations was triggered, and so the therapist took this as an occasion to teach Andrea how to address this distortion. By this time, Andrea reported that she no longer had panic attacks, but she was still terrified of having them in the future: “I don't even want to pronounce the name of it; you know what I'm talking about. Those moments were so awful. I was feeling captive wherever I was going; fear was with me all the time.” The therapist showed her that she had made important progress, and encouraged and helped her to find strength and motivation to continue. This session was the longest, lasting 57 minutes.

\section{$\underline{\text { Skype Session } 6}$}

Because of the recurrent worries Andrea expressed, the therapist decided to include an additional module, one that is normally dedicated to dealing with worries in the Generalized Anxiety Disorder program. Andrea learned a new technique for dealing with worries and she promised to use it.

But again, Andrea expressed concerns about her performance in reading the recommended modules. "I'm so stressed about this. I'm afraid that I won't remember anything after reading a new module,” and she continued, “You won't trick me into doing exposure modules. I'm terrified about doing exposure exercises since the second module.” In response, the therapist insisted that Andrea do the exercises she had learned so far, so that she would be ready to do the exposure exercises, step by step.

\section{$\underline{\text { Skype Session } 7}$}

In this session, Andrea's unconscious thoughts and beliefs were challenged according to the procedures presented in Module 9, “Changing maladaptive unconscious cognitions.” Again, the therapist offered a model on how to identify and challenge an unconscious belief, i.e., Andrea's belief that "I can’t manage to do anything on my own."

During the session, they used humor quite a lot. Unfortunately, although the frequency and intensity of Andrea's panic attacks had dropped substantially since the beginning of treatment, Andrea had not changed her attitude about panic attacks; she was still extremely afraid of those sensations: "Yesterday I got on the bus, but the driver didn't leave right away. Within seconds, I started to think that it was taking too long to leave the station. A panic attack will surely get me.” She did not have a full panic attack, but she was very nervous about what could have happened to her: "I am not able to do this. I will never get out of this nightmare." She also expressed wishful thinking: "If there would only be a magic pill, but I know there isn't."

The therapist encouraged her to continue practicing the anxiety reducing exercises, but also insisted that she start to seriously consider making gradual changes in her life.

\section{Skype Session 8.}

This session was dedicated to Module 10, interoceptive exposure, and Andrea found the inner strength to practice some of the exercises with the therapist. At the beginning, she was 
A.M. Ciuca, T. Berger, \& M. Miclea

Pragmatic Case Studies in Psychotherapy, http://pcsp.libraries.rutgers.edu/

Volume 13, Module 3, Article 1, pp. 173-216, 11-11-17 [copyright by authors]

terrified. "It's awful. I only showed up because I'd feel guilty because of you, but this is atrocious." At the end, though, Andrea admitted that it was much better than she expected.

As homework, Andrea was instructed to continue with the exercises learned so far and, once every other day, practice the interoceptive exposure exercises that induced the kind of sensations most similar to those she felt during panic attacks (e.g., eating something very hot or spicy; spinning in a chair for 1 minute; and staying in a hot and crowded place).

\section{$\underline{\text { Skype Session } 9}$}

This session was dedicated to discussing and planning for Module 11, the exteroceptive exposure exercises. Since the third week of the treatment, Andrea was encouraged to try doing things on her own, and she did start to walk alone for short distances. Together with the therapist, she developed an exposure plan and promised that she would start to practice the exercises more systematically.

\section{Skype Session 10.}

This last session was dedicated to discussing the three last modules that she hadn't yet covered: Module 13, how to bring back positive emotions into her life, and Module 15, making changes in her life through behavioral activation and finding the strength to cultivate her passions, such as reading and writing.

The therapist also discussed with Andrea the importance of continuing the strategies she had learned through the PAXPD treatment and how to prevent and react in case of a relapse (see Module 14). Andrea acknowledged the progress she made so far, but she also knew that it was just the beginning, especially regarding the exposure exercises and the life decisions she needed to make. She was sad and scared about losing the support of her therapist, but she promised to continue the battle with her anxiety and low mood.

\section{THERAPY MONITORING, PROGRAM USE, AND PROGRAM COMPLIANCE}

\section{Maria's Experience in the Program}

Maria was committed to the program and relied a lot on the Skype Sessions she had with her therapist. In total, there were 10 such guidance sessions and the time spent was 312 minutes, with a range between 21 and 43 minutes per session and an average of 31.2 minutes per session. Some sessions took longer because of the comorbidity problems that needed to be addressed.

Maria went through all the recommended modules once or twice (and three times for the autogenic training module, because she encountered some problems with this relaxation technique), and she uploaded most of the required worksheets (such as panic attack diaries, the attentional biases list, the cognitive restructuring worksheets, the exposure hierarchy form, the exposure exercise worksheets, and the personal strengths worksheet). 
The total amount of time Maria spent in the platform was 425 minutes. During the treatment period, the asynchronous communication was used about 15 times and mostly involved short messages for planning the Skype Sessions and the next modules. On two occasions it was also used for asking and providing support in overcoming some obstacles encountered during homework practice. The time spent in the platform was less than the average time spent by the group of clients in her experimental condition of the RCT. This can be explained by Maria being very self-motivated and focusing more on practicing the recommended exercises and integrating them into her everyday life.

During her treatment, Maria monitored the frequency of panic attacks, and her mood was checked at the beginning and end of each module. The results are presented in Figures 1, 3, and 4. As can be seen, Maria had a low mood for the first weeks of the treatment. During that time period, she was still having panic attacks and her depressive symptoms worsened. For this reason, an additional module of the panic program was included, one dealing with comorbid depression symptoms through the behavioral activation technique. This proved to be an effective therapeutic decision: Maria started to feel better and she continued to display a good mood for the next few weeks, although it got worse again three weeks before she ended treatment.

During that time period, she was home for Easter vacation and she had another panic attack. After this relapse, Maria was afraid she would never get better, which made her very upset. The panic attack was triggered by both spending time alone in the same house where she experienced a panic attack for the first time a year before, and by experiencing some family problems. However, Maria continued her recommended exercises, especially the exposure activities, and by the time she completed the last non-optional module, which was Module 14 involving, relapse prevention, her mood had already improved.

The anxiety tracker in Figure 4 shows how Maria's anxiety changed during treatment. Her anxiety was high at the beginning and decreased after each module, with the exception of Module 4, where she had some problems with putting the autogenic training exercises into practice, and Module 10, which was dedicated to preparing for the exposure exercises. Again, the graph shows the effect of the panic attack she had during Easter vacation, four weeks before finishing treatment. After the time spent at home, Maria rated her anxiety at 6 on an intensity scale from 0 to 10 . Soon afterwards it dropped to 4 and then to 3 , as she reported in the feedback questionnaire.

\section{Andrea's Experience in the Program}

Andrea was committed to the program, yet she was afraid of doing the exercises, especially the exposure strategies. She needed a lot of attention from the therapist and developed a strong therapeutic relationship. There were 10 Skype guidance sessions in total, and even though these sessions were planned to last between 15 and 30 minutes, Andrea asked for additional time with her therapist. The time range for these sessions was 28-57 minutes, with a total of 434 minutes and an average of 43.4 minutes (compared to Maria's average of 31.2 minutes per session). 
Andrea went through all the recommended modules, even 2, 3, or 5 times, and she uploaded most of the required worksheets. However, her behavior in the online PAXPD program seemed confused in the beginning (for example, she hadn't managed to read the first panic module, Module 1, until two weeks into the program, and she kept going back and forth between module components). Also, Andrea frequently used the personal diary to comment on her journey through the platform. The total amount of time spent in the platform was 1020 minutes. During the treatment period, the asynchronous communication was used about 20 times, consisting mostly of short messages for setting a date for the Skype sessions and technical aspects of using PAXPD. Compared to Maria, Andrea used the platform much more (Maria's total time in the program was only 425 minutes), including Andrea writing in the optional personal journal; but Andrea was able to transfer fewer of the interventions into her everyday life than Maria.

Andrea tried to put the daily exercises into practice, but most of the time she reported that it was hard to integrate them into her daily schedule. She generally practiced the breathing technique and the autogenic training just once a day, and did not implement the recommendations for physical exercise. She used the technique to challenge and modify conscious and unconscious thoughts and beliefs several times, but not enough to make the necessary long-term changes. She also practiced the exposure exercises-mostly interoceptivebut only for about two weeks (2 or 3 times per week).

In the last weeks of her treatment, Andrea was able to go to a nearby market alone and to pass through a crowded intersection she had previously avoided. Andrea went out with a friend twice, and managed to return home alone once. She started to read books again and even wrote two poems, which she shared with her therapist.

During her treatment, Andrea also kept a panic-attack-frequency-monitoring sheet and her mood was checked at the beginning and end of each module. The results are presented in Figures 2, 5, and 6. As can be seen, Andrea had a low mood for the first weeks of the treatment, as she still experienced intense panic attacks. Her panic attacks slowly disappeared, which improved her mood, but her mood dropped again after a new, unexpected panic attack. From that point on, Andrea maintained that her mood was relatively high, yet she was still unhappy with her life situation: single, separated from her sister, and stuck with a job she hated: "I wonder if this is all that life has to offer me; is it ever going to change or is this all I'm ever going to accomplish? Will I ever be able to use my creativity?" She still had a few panic attacks in the last part of the treatment, but the intensity was lower, and most were triggered by doing exposure exercises.

The anxiety tracker in Figure 6 shows the anxiety levels Andrea reported before and after reading each treatment module. At the beginning, her anxiety was higher before reading than after reading each module, but then dropped after she adjusted to the treatment. It is important to mention that Andrea felt safe at home and most of her panic attacks happened on the street, in the bus, or at work. This explains why her anxiety levels were low while she was reading the modules, in the safety of her house. 
A.M. Ciuca, T. Berger, \& M. Miclea

Pragmatic Case Studies in Psychotherapy, http://pcsp.libraries.rutgers.edu/

Volume 13, Module 3, Article 1, pp. 173-216, 11-11-17 [copyright by authors]

\section{Advantages and Disadvantages of Offering Treatment for Panic Disorder Through an Internet-Based Intervention with Skype Guidance Sessions with a Therapist}

In the first part of the intervention, both clients viewed working from home, which they considered to be a safe environment, as less threatening than seeing a therapist in his/her office. In the last part of the treatment, both mentioned that seeing their therapist in a face-to-face session would not have been a problem anymore.

They also appreciated the fact that they could revisit each module as often as needed. Andrea considered the platform very well organized and useful: "I liked the fact that important information is highlighted. I also appreciate the summary part and the explanatory videos very much. The program helped me understand my disorder and also showed the right solutions to reduce it or fight against it." Maria also mentioned in the feedback questionnaire, "From my point of view, the platform is very well structured and offers all the necessary information. I especially liked that the modules addressed the exact problems I was facing and it convinced me that there is a solution for them, so now I know what I'm dealing with and how to face any situation.”

As a suggestion for improvement, Andrea mentioned the problems she was having with the quality of some videos "the sound was too low in some videos, and I had some problems understanding.” Another technical aspect she mentioned was the ease of filling in the questionnaires or work sheets and uploading them onto the platform.

Both clients and their therapist mentioned that using asynchronous and synchronous communication provided more flexibility and meant losing less time for each session. It also made it much easier to postpone or reschedule a session, even on short notice.

Technical problems arose in the case of both clients. For example, the first Skype Session with Andrea took place after two unsuccessful tries. During the first try, the internet connection was too slow, and the patient and therapist were unable to hear each other. During treatment, similar Skype problems occurred a few times, such as a slow connection affecting the quality of the sound or the image. These technical problems made the sessions longer and sometimes affected the practice of certain exercises. For example, inducing relaxation through autogenic training was repeated twice with Andrea because of small interruptions.

Real-time audio-video sessions can at least partially provide the advantages of directly seeing and observing a client during therapy, but using Skype allows access only to the face or upper body of the client. This can also create an unpleasant sensation of being too close to the other person. Frequently, even in the last part of the treatment, Andrea was avoiding direct eye contact with her therapist, and in some cases this was also true for Maria. The therapist noted that at least three or four times there was not enough light in Maria's room, which made her misperceive some sounds (e.g. once she thought that Maria was crying, but in fact she had a cold). 
The therapist had previous experience and positive results using PAXonline and Skype as a way of delivering psychotherapy services, but she also felt that during certain phases of the therapy it would have been helpful to be in the same room with her clients: "I like to use my hands a lot when I explain things and I put a lot of energy and enthusiasm in my work, but I'm afraid that my clients do not receive all of my positive energy when I am not in the same room with them."

\section{CONCLUDING EVALUATION OF THE THERAPY'S PROCESS AND OUTCOME}

\section{Results on the Primary and Secondary Outcome Measures (Table 2)}

$\underline{\text { Maria }}$

As shown in Table 2, when Maria started the treatment, her score on the Panic Disorder Severity Scale was 18 . During treatment the score dropped to 8 , then 5 , and at post-treatment she scored 3. A cut-off score of 6 may discriminate between the presence and absence of current DSM-IV Panic Disorder and a cut-off score of 14 may discriminate between mild and severe Panic Disorder (Furukawa et al., 2009). The diagnostic report after the clinical interview stated that Maria no longer had a panic disorder, only residual symptoms and subclinical agoraphobia. Also, she no longer experienced depressive symptoms. The GAF score improved, from 50 at the beginning of the treatment to 80 at the end. The results of secondary measures were in line with these conclusions. On a scale from 0 (not at all anxious) to 10 (the most severe anxiety), Maria reported that her anxiety level was 10 at the beginning of the treatment, and 3 at the end of the treatment.

\section{$\underline{\text { Andrea }}$}

As shown in Table 2, when she started the treatment, Andrea's Panic Disorder Severity Scale was 18. During treatment it dropped to 14, then 12, and at post-treatment she scored 11. The diagnostic report after the clinical interview revealed that she still had a Panic Disorder with agoraphobia, but the intensity dropped from severe to moderate. She had managed to go out alone, but only for short distances. She still experienced depressive symptoms and generalized anxiety disorder symptoms, but their intensity had dropped.

Andrea's GAF score improved from 45 at the beginning of the treatment to 65 at the end of treatment. The results of secondary measures confirmed the improvement, as did the conclusions drawn from the diagnostic interview. On a scale from 0 (not at all anxious) to 10 (the most severe anxiety), Andrea reported that at the beginning of the treatment her anxiety level was 10 , and at the end of the treatment her anxiety level was 6 . 


\section{Results on Additional Measures (see Table 4)}

\section{$\underline{\text { Social Support (SS-5) and Therapeutic Alliance (WAI-S) }}$}

Maria experienced high social support from the beginning until the end of the treatment (maximum score of 28 on the Social Support Scale [SS-5], an abbreviated version of the Medical Outcomes Study Social Support Scale, which assesses the perceived availability of social support [Sherbourne \& Stewart, 1991]). However, Andrea did not experience as much support (at the beginning her score was 19, then it dropped to 15).

The therapeutic alliance, as measured by the Working Alliance Inventory (WAI), was measured after the first and the fourth session. For Maria the Tasks and Goals subscales didn't change at all; it was at the highest score of 28 at both time points. In contrast, at the beginning, Andrea showed lower levels of therapeutic alliance on the Tasks and Goals subscales, although they did go up to maximum at the second measurement point. Andrea's Bond score on the WAI was at the maximum of 28 at both time points and higher than Maria's. This might have reflected Andrea’s higher score on dependency (see “personality traits” section below).

\section{Treatment Credibility (CEQ)}

Expectancy and credibility ratings differed between the two clients. Maria considered the treatment highly credible (maximum score in the Credibility subscale) and had high expectancy for the success of therapy. Andrea considered the treatment less credible and her expectancies for improvement were lower. At the second point of assessment, both had improved their expectancies and showed higher credibility in the treatment.

\section{$\underline{\text { Personality Traits }}$}

Personality traits were also measured for both clients at the beginning of the treatment. Maria scored in the normal range on the Dependent Personality Subscale of the OMNI-IV (Loranger, 2001), while Andrea's results were above the clinical cut-off point (Table 3). This parallels clinical observations made by Andrea's therapist, who judged that she might be suffering from a Dependent Personality Disorder.

Consistent with the dependency finding, Andrea also showed low levels of autonomy, measured with the Personal Autonomy Questionnaire (Albu, 2007), while Maria scored in the normal range on this measure.

\section{Program Usability}

After the first session and at post-treatment, we measured the usability of the PAXonline platform on Lewis and Sauro's (2009) System Usability Scale (SUS). The results indicate that Maria had very high usability scores from the beginning until the end.

Andrea indicated substantially lower usability scores (67.5 at the first measurement, and just 55 out of 100 at the last measurement). Although Andrea managed to accomplish all of the 
necessary tasks, she asked for additional technical support, including concerns for tasks that did not have much to do with the platform per se, e.g., she did not know how to load the audio autogenic training files onto her mobile phone.

\section{Status at Follow-Up}

$\underline{\text { Maria }}$

The good results were maintained and even improved for Maria at follow-up evaluations. At the 3-month follow-up, she mentioned that a few weeks earlier, she lost someone dear to her and feared a relapse, but it did not happen. She continued to practice all the exercises she had learned during treatment and that helped her avoid a relapse and kept her good mental health status.

$\underline{\text { Andrea }}$

At the post-treatment evaluation, Andrea still met the criteria for panic disorder with agoraphobia, but there was a clear tendency toward improvement. This tendency for improvement continued, and she felt better and better at follow-up measurements. For example, her Panic Disorder Severity Scale (PDSS-SR) score dropped to 6 at one-month follow-up, and then to 1 at three-month follow-up). Unfortunately, we are unable to know for sure whether she recovered from her panic disorder and agoraphobia, since there was no follow-up clinical interview.

\section{Cross-Case Comparisons}

\section{Different Outcomes, Different Life Contexts, and Different Personalities}

At the beginning of treatment, both Maria and Andrea had a severe panic disorder with agoraphobia. They used the same Internet-based treatment program, PAXonline for Panic Disorder, and they received guidance from the same therapist. Both showed significant improvement in their mental status at the end of the treatment, but only Maria recovered and no longer fulfilled the DSM-IV criteria for Panic Disorder. At the post-treatment clinical interview, Andrea still fulfilled the diagnostic criteria for Panic Disorder with Agoraphobia, although the intensity had decreased from an intense to a moderate level.

The two patients experienced completely different life contexts. Maria, who obtained the better outcome, was a young student with very high social support and with many opportunities ahead. Andrea, with the poorer outcome, was older, had lower levels of social support, and was in what she considered to be a dead-end job. She lacked any personal projects or plans for the future and was very much afraid of physical sensations.

Both clients showed anxious personality traits, but only Andrea showed dependent personality traits and she had lower levels of personal autonomy. Andrea lacked trust in herself, and perhaps as a result, she also had lower expectations of treatment outcome. Andrea found it harder to use the online platform and developed a dependency on her therapist. While Andrea 
used the recommended cognitive-behavioral strategies for reducing anxiety symptoms and increasing positive emotions, she practiced them inconsistently, showing ambivalent feelings toward these strategies.

\section{At Different Points on the Stages-of-Change Continuum}

After the last session, Andrea continued to work with the platform by reading the additional modules dedicated to problem solving and reducing depressive symptoms. From her journal notes and work sheets, we could see that by that time Andrea was able to clearly identify her main problems - including lack of physical exercise, unhealthy eating, her job, her lack of purpose and projects, her lack of friends, and her lack of autonomy, and she was determined to address them one by one.

According to Prochaska, Norcross, and DiClemente’s (2013) Stages-of-Change model, the two clients were in different stages at the beginning of treatment, and "the amount of progress clients make during treatment tends to be a function of their pretreatment stage of change” (Prochaska et al., 2013, p. 13). Specifically, Maria was more of an action-oriented person, and at the beginning of therapy she was prepared and ready to implement change and had the necessary support from her friends to do so.

In contrast, Andrea was a more reflective person, and she found herself in a different stage of change. She was aware of her situation and felt overwhelmed by it, so she needed more time to build trust and start putting the recommended exercises into consistent practice. She saw a possible friend in her therapist: someone she could talk to and could help her understand what went wrong with her life. The panic attacks and severe agoraphobia were main concerns for Andrea, but she needed more from the therapy. This became clear after analyzing several aspects of her treatment: her answers to the Task and Goal subscales from WAI-S, in which she had lower scores at the beginning of therapy than Maria; Andrea's evaluation in a feedback questionnaire where she answered with a lower rating than Maria concerning how much the program addressed her needs and was useful to her; and Andrea's tendency to go into details and depart from the clear objectives of each meeting.

Unfortunately, the standardized, Internet-based program could not fully address Andrea's additional needs. Her therapist was supportive, but also directive and task-oriented. The therapist tried and managed fairly well to address the personal needs and additional problems of her clients (depressive symptoms and generalized anxiety symptoms), but the CBT intervention was offered in a randomized controlled trial, so a specific agenda needed to be followed in a defined amount of time.

While the therapist readily addressed Maria's depressive symptoms and changed the relaxation technique for her when it was necessary, in Andrea's case, the therapist addressed Andrea's depressive symptoms, but not directly. Also, the therapist approached Andrea's generalized anxiety disorder symptoms only in the second part of the treatment. Due to Andrea's avoidant personality style and confusion at the beginning (when she failed to read the modules in the proper order), there was a constant delay in following the recommended agenda. This took 
away time from the exposure exercises and may explain not only the slower progress registered at post-treatment, but also the improvements observed at follow-up points.

\section{Conclusions}

We can draw several conclusions after analyzing the two case studies. First, for each client, the ICBT program PAXonline plus the Skype guidance sessions proved useful. In fact, the majority of the participants in this group of our RCT study showed substantial improvements (Ciuca et al., 2017, under review). However, the impact of ICBT-plus-guidance sessions may be influenced by several factors.

\section{The Client's Individual Life Context}

One factor is the personal life-context of each client during the therapy. A supportive or at least a neutral life-context seems to help the therapy process, perhaps making the program impact more substantial. On the contrary, a negative personal life-context (as in Andrea's general situation, or during Maria's Easter vacation period) can interfere with the ICBT process. Because of its manualized nature, ICBT programs are not sensitive to the serendipitous contexts of a client's life during treatment, and this limitation could be compensated for by providing more therapist support offered via Skype.

The Comorbidities and Personality Traits of the Clients.

Andrea's behavioral avoidance of situations and her reflective style impacted upon how she approached the therapeutic modules. She had a recurrent avoidant attitude toward the modules during the therapy process. This attitude was reflected in several ways: (a) a tendency to impose a secondary agenda during Skype sessions (e.g., a focus on irrelevant technicalities in the PAXonline program); (b) excessive questioning of minor, less relevant aspects of therapy; (c) skipping modules or complex exercises, such as autogenic training; (d) complaining about too much information or too many exercises; and (e) asking for reassurance from her therapist in almost every session. This avoidant attitude toward the therapeutic modules-a particular manifestation of her more general avoidant style-interfered with the process of ICBT and reduced its positive impact, at least in the short term.

\section{The Role of the Therapist}

Another conclusion refers to the important role that the psychotherapist plays in the ICBTplus- guidance-sessions via Skype, even though that role is much more limited than in traditional, face-to-face therapy. Specifically, in the guidance role, the therapist is a facilitator in the assimilation process of therapeutic opportunities embedded in each module. The therapist facilitates (a) the understanding of the modules (e.g., offering additional explanations and details, using metaphors, and tailoring the content); (b) the practice of various exercises (via modeling); and (c) the motivation of the clients (by offering feedback, including contingent reinforcement for successful participation, by challenging their unrealistic expectations or avoidant attitudes, by rescheduling the modules, and by adjusting the content to the specific needs of each client). 
The efficacy and effectiveness studies conducted so far allow us to expect that Internetbased interventions can contribute substantially to reducing the gap between mental health care needs and service use by providing better access to quality treatment. However, in order to use these solutions more efficiently, we need to find the best ways to tailor the interventions according to the individual characteristics of clients, including their severity of symptoms and comorbidity problems, their personality traits, their life context, their stage-of-change position, and so forth. Offering real-time, audio-video guidance via Skype is one way of tailoring these interventions and increasing their positive impact. However, each patient has his or her own internal process of change and individual pace, and that is a significant challenge in tailoring guided Internet-based therapy to the needs of each individual client.

\section{REFERENCES}

Abbott, J.A.M., Klein, B., \& Ciechomski, L. (2008). Best practices in online therapy. Journal of Technology in Human Services, 26(2-4), 360-375.

Albu, M. (2007). Un nou instrument pentru evaluarea autonomiei personale la adolescenţi/ A new instrument for personal autonomy evaluation in adolescents. Anuarul Institutului de Istorie George Bariţ din Cluj-Napoca. Seria Humanistica, V, 99-114.

Andersson, E., Enander, J., Andren, P., Hedman, E., Ljotsson, B., Hursti, T., . . Ruck, C. (2012). Internet-based cognitive behaviour therapy for obsessive-compulsive disorder: a randomized controlled trial. Psychol Med, 42(10), 2193-2203. doi: $10.1017 /$ S0033291712000244

Andersson, G. (2015). The Internet and CBT: A clinical guide: CRC Press, Taylor\& Francis.

Andersson, G., Cuijpers, P., Carlbring, P., Riper, H., \& Hedman, E. (2014). Guided Internetbased vs. face-to-face cognitive behavior therapy for psychiatric and somatic disorders: a systematic review and meta-analysis. World Psychiatry, 13(3), 288-295. doi: Doi 10.1002/Wps.20151

Andersson, G., \& Titov, N. (2014). Advantages and limitations of Internet-based interventions for common mental disorders. World Psychiatry, 13(1), 4-11. doi: 10.1002/wps.20083

Andrews, G. (2003). The treatment of anxiety disorders: Clinician's guide and patient manuals (2nd ed.). Cambridge: Cambridge University Press.

Barak, A., Klein, B., \& Proudfoot, J. G. (2009). Defining internet-supported therapeutic interventions. Ann Behav Med, 38(1), 4-17. doi: 10.1007/s12160-009-9130-7

Barkham, M., Stiles, W. B., \& Shapiro, D. A. (1993). The shape of change in psychotherapy: longitudinal assessment of personal problems. J Consult Clin Psychol, 61(4), 667-677.

Baumeister, H., Reichler, L., Munzinger, M., \& Lin, J. (2014). The impact of guidance on Internet-based mental health interventions-A systematic review. Internet Interventions, 1(4), 205-215.

Beattie, A., Shaw, A., Kaur, S., \& Kessler, D. (2009). Primary-care patients' expectations and experiences of online cognitive behavioural therapy for depression: a qualitative study. Health Expectations, 12(1), 45-59. doi: 10.1111/j.1369-7625.2008.00531.x

Bendelin, N., Hesser, H., Dahl, J., Carlbring, P., Nelson, K., \& Andersson, G. (2011). Experiences of guided Internet-based cognitive-behavioural treatment for depression: A qualitative study. BMC Psychiatry, 11(1), 107. 
Berger, T., Boettcher, J., \& Caspar, F. (2014). Internet-Based Guided Self-Help for Several Anxiety Disorders: A Randomized Controlled Trial Comparing a Tailored With a Standardized Disorder-Specific Approach. Psychotherapy, 51(2), 207-219. doi: Doi 10.1037/A0032527

Berger, T., Caspar, F., Richardson, R., Kneubühler, B., Sutter, D., \& Andersson, G. (2011). Internet-based treatment of social phobia: a randomized controlled trial comparing unguided with two types of guided self-help. Behav Res Ther, 49(3), 158-169.

Berger, T., Hammerli, K., Gubser, N., Andersson, G., \& Caspar, F. (2011). Internet-based treatment of depression: a randomized controlled trial comparing guided with unguided self-help. Cogn Behav Ther, 40(4), 251-266. doi: 10.1080/16506073.2011.616531

Bergstrom, J., Andersson, G., Ljotsson, B., Ruck, C., Andreewitch, S., Karlsson, A., . . . Lindefors, N. (2010). Internet-versus group-administered cognitive behaviour therapy for panic disorder in a psychiatric setting: a randomised trial. Bmc Psychiatry, 10. doi: Artn 54Doi 10.1186/1471-244x-10-54

Boettcher, J., Carlbring, P., Renneberg, B., \& Berger, T. (2013). Internet-Based Interventions for Social Anxiety Disorder - an Overview. Verhaltenstherapie, 23(3), 160-168. doi: Doi 10.1159/000354747

Botella, C., Gallego, M. J., Garcia-Palacios, A., Guillen, V., Banos, R. M., Quero, S., \& Alcaniz, M. (2010). An Internet-Based Self-Help Treatment for Fear of Public Speaking: A Controlled Trial. Cyberpsychology Behavior and Social Networking, 13(4), 407-421. doi: DOI 10.1089/cyber.2009.0224

Carlbring, P., Bohman, S., Brunt, S., Buhrman, M., Westling, B. E., Ekselius, L., \& Andersson, G. (2006). Remote treatment of panic disorder: A randomized trial of internet-based cognitive behavior therapy supplemented with telephone calls. American Journal of Psychiagtry, 163(12), 2119-2125.

Carlbring, P., Nilsson-Ihrfelt, E., Waara, J., Kollenstam, C., Buhrman, M., Kaldo, V., . . . Andersson, G. (2005). Treatment of panic disorder: live therapy vs. self-help via the Internet. Behav Res Ther, 43(10), 1321-1333.

Chambless, D. L., Caputo, G. C., Bright, P., \& Gallagher, R. (1984). Assessment of Fear of Fear in Agoraphobics - the Body Sensations Questionnaire and the Agoraphobic Cognitions Questionnaire. Journal of Consulting and Clinical Psychology, 52(6), 1090-1097. doi: Doi 10.1037/0022-006x.52.6.1090

Ciuca, A.M. (2016). PAXonline: Computer mediated psychotherapy for anxiety disorders. Extended abstract of Ph.D. Thesis, Babeş-Bolyai University, Cluj-Napoca, Romania. Available: https://www.google.com/search?q=Ciuca,+A.M.+(2016).+PAXonline\%3A+Computer $+\mathrm{m}$ ediated+psychotherapy+for+anxiety+disorders.+Extended+abstract+of +Ph.D.+Thesis, + B abeș-Bolyai+University,+Cluj-Napoca,+Romania.+Available\%3A\&oq=Ciuca,+A.M.+(2

Ciuca, A.M., Albu, M., Perţe, A., Budău, O., Miclea, Ş., \& Miclea, M. (2011). The Romanian adaptation of the Psychiatric Diagnostic Screening Questionnaire (PDSQ). Cognition, Brain, Behavior, XV, 69-93.

Ciuca, A. M., Berger, T., Crişan, L. G., \& Miclea, M. (2016). Internet-based treatment for Romanian adults with panic disorder: protocol of a randomized controlled trial comparing a Skype-guided with an unguided self-help intervention (the PAXPD study). Bmc Psychiatry, 16(1), 1-16. doi: 10.1186/s12888-016-0709-9 
A.M. Ciuca, T. Berger, \& M. Miclea

Pragmatic Case Studies in Psychotherapy, http://pcsp.libraries.rutgers.edu/

Volume 13, Module 3, Article 1, pp. 173-216, 11-11-17 [copyright by authors]

Ciuca, A. M., Berger, T., Crisan, L. G., \& Miclea, M. (2017, under review). Internet-based treatment for panic disorder: Three-arm randomized controlled trial comparing guided (via real time video sessions) with unguided self-help treatment and a waitlist controlPAXPD study results. Journal of Anxiety Disorders.

Clark, D. A., \& Beck, A. T. (2011). Cognitive therapy of anxiety disorders: Science and practice: Guilford Press.

Clum, G. A., Broyles, S., Borden, J., \& Watkins, P. L. (1990). Validity and Reliability of the Panic Attack Symptoms and Cognitions Questionnaires. Journal of Psychopathology and Behavioral Assessment, 12(3), 233-245. doi: Doi 10.1007/Bf00960620

Craske, M. G., \& Barlow, D. H. (2007). Panic Disorder and Agoraphobia. In D. H. Barlow (Ed.), Clinical Handbook of Psychological Disorders: A Step-by-Step Treatment Manual (4th ed.).

Dattilio, F. M., Edwards, D. J., \& Fishman, D. B. (2010). Case studies within a mixed methods paradigm: toward a resolution of the alienation between researcher and practitioner in psychotherapy research. Psychotherapy, 47(4), 427-441. doi: 10.1037/a0021181

Devilly, G. J., \& Borkovec, T. D. (2000). Psychometric properties of the credibility/expectancy questionnaire. Journal of Behavior Therapy and Experimental Psychiatry, 31(2), 73-86. doi: Doi 10.1016/S0005-7916(00)00012-4

Donkin, L., \& Glozier, N. (2012). Motivators and motivations to persist with online psychological interventions: a qualitative study of treatment completers. J Med Internet Res, 14(3), e91. doi: 10.2196/jmir.2100

Farvolden, P., Denisoff, E., Selby, P., Bagby, R. M., \& Rudy, L. (2005). Usage and longitudinal effectiveness of a Web-based self-help cognitive behavioral therapy program for panic disorder. J Med Internet Res, 7(1), e7. doi: 10.2196/jmir.7.1.e7

Fishman, D. B. (2008, June). Case studies of good and poor outcome in RCT clients: A new, "Individual-Case-Comparison" method for psychotherapy research. Paper presented at the Society of Psychotherapy Research, Barcelona, Spain.

Fishman, D. B. (2011). The "Individual-Case-Comparison" Method for systematically comparing good-outcome and poor-outcome RCT clients: Editor's introduction. Pragmatic Case Studies in Psychotherapy, 7(2), Article 1, 242-245. Available: http://pcsp.libraries.rutgers.edu

Fishman, D. B. (2013). The pragmatic case study method for creating rigorous and systematic, practitioner-friendly research. Pragmatic Case Studies in Psychotherapy, 9(4), Article 2, 403-425. Available: http://pcsp.libraries.rutgers.edu

Fishman, D.B., Messer, S.B., Edwards, D.J.A., \& Dattilio, F.M. (2017). Case studies within psychotherapy trials: Integrating qualitative and quantitative methods. New York: Oxford.

Florescu, S., Ciutan, M., Popovici, G., Galaon, M., Ladea, M., \& Petukhova, M. (2009). The Romanian Mental Health Study: main aspects of lifetime prevalence and service use of DSM-IV disorders [Romanian] Management in Health, 13(3), 22-30.

Furmark, T., Carlbring, P., Hedman, E., Sonnenstein, A., Clevberger, P., Bohman, B., . . . Andersson, G. (2009). Guided and unguided self-help for social anxiety disorder: randomised controlled trial. British Journal of Psychiatry, 195(5), 440-447. doi: DOI 10.1192/bjp.bp.108.060996 
Furukawa, T. A., Shear, M. K., Barlow, D. H., Gorman, J. M., Woods, S. W., Money, R., .. . Leucht, S. (2009). Evidence-Based Guidelines for Interpretation of the Panic Disorder Severity Scale. Depression and Anxiety, 26(10), 922-929. doi: Doi 10.1002/Da.20532

Halmetoja, C. O., Malmquist, A., Carlbring, P., \& Andersson, G. Experiences of internetdelivered cognitive behavior therapy for social anxiety disorder four years later: A qualitative study. Internet Interventions, 1(3), 158-163. doi: 10.1016/j.invent.2014.08.001

Hedman, E., Ljotsson, B., \& Lindefors, N. (2012). Cognitive behavior therapy via the Internet: a systematic review of applications, clinical efficacy and cost-effectiveness. Expert Rev Pharmacoecon Outcomes Res, 12(6), 745-764. doi: 10.1586/erp.12.67

Hedman, E., Ljotsson, B., Ruck, C., Bergstrom, J., Andersson, G., Kaldo, V., . . Lindefors, N. (2013). Effectiveness of Internet-based cognitive behaviour therapy for panic disorder in routine psychiatric care. Acta Psychiatrica Scandinavica, 128(6), 457-467. doi: Doi 10.1111/Acps.12079

Horvath, A. O., \& Greenberg, L. S. (1989). Development and validation of the Working Alliance Inventory. Journal of Counseling Psychology, 36(2), 223.

Houck, P. R., Spiegel, D. A., Shear, M. K., \& Rucci, P. (2002). Reliability of the self-report version of the Panic Disorder Severity Scale. Depression and Anxiety, 15(4), 183-185. doi: Doi 10.1002/Da.10049

Ivarsson, D., Blom, M., Hesser, H., Carlbring, P., Enderby, P., Nordberg, R., \& Andersson, G. (2014). Guided internet-delivered cognitive behavior therapy for post-traumatic stress disorder: A randomized controlled trial. Internet Interventions, 1(1), 33-40. doi: http://dx.doi.org/10.1016/j.invent.2014.03.002

Jacobson, N.S., \& Truax, P. (1991). Clinical significance: A statistical approach to defining meaningful change in psychotherapy research. Journal of Consulting and Clinical Psychology, 59, 12-19.

Kessler, R. C., Berglund, P., Demler, O., Jin, R., Merikangas, K. R., \& Walters, E. E. (2005). Lifetime prevalence and age-of-onset distributions of DSM-IV disorders in the National Comorbidity Survey Replication. Arch Gen Psychiatry, 62(6), 593-602. doi: 10.1001/archpsyc.62.6.593

Kiropoulos, L. A., Klein, B., Austin, D. W., Gilson, K., Pier, C., Mitchell, J., \& Ciechomski, L. (2008). Is internet-based CBT for panic disorder and agoraphobia as effective as face-toface CBT? Journal of Anxiety Disorders, 22(8), 1273-1284. doi: DOI 10.1016/j.janxdis.2008.01.008

Klein, B., Richards, J. C., \& Austin, D. W. (2006). Efficacy of internet therapy for panic disorder. Journal of Behavior Therapy and Experimental Psychiatry, 37(3), 213-238. doi: DOI 10.1016/j.jbtep.2005.07.001

Krieger, T., Meyer, B., Sude, K., Urech, A., Maercker, A., \& Berger, T. (2014). Evaluating an emental health program ("deprexis") as adjunctive treatment tool in psychotherapy for depression: Design of a pragmatic randomized controlled trial. BMC Psychiatry, 14(1), 285.

Kroenke, K., Spitzer, R. L., Williams, J. B. W., \& Lowe, B. (2010). The Patient Health Questionnaire Somatic, Anxiety, and Depressive Symptom Scales: A systematic review. General Hospital Psychiatry, 32(4), 345-359. doi: DOI 10.1016/j.genhosppsych.2010.03.006 
Leahy, R. L., \& Holland, S. J. (2000). Treatment plans and interventions for depression and anxiety disorders. New York ; London: Guilford Press.

Lewis, J. R., \& Sauro, J. (2009). The Factor Structure of the System Usability Scale. Human Centered Design, Proceedings, 5619, 94-103.

Loranger, A. (2001). OMNI Personality inventories. Professional manual. Lutz, FL: Psychological Assessment Resources.

Ly, K. H., Janni, E., Wrede, R., Sedem, M., Donker, T., Carlbring, P., \& Andersson, G. (2015). Experiences of a guided smartphone-based behavioral activation therapy for depression: A qualitative study. Internet Interventions, 2(1), 60-68. doi: 10.1016/j.invent.2014.12.002

Maercker, A., Bachem, R. C., Lorenz, L., Moser, C. T., \& Berger, T. (2015). Adjustment Disorders Are Uniquely Suited for eHealth Interventions: Concept and Case Study. JMIR Mental Health, 2(2), e15. doi: 10.2196/mental.4157

Mewton, L., Smith, J., Rossouw, P., \& Andrews, G. (2014). Current perspectives on Internetdelivered cognitive behavioral therapy for adults with anxiety and related disorders. Psychol Res Behav Manag, 7, 37-46. doi: 10.2147/PRBM.S40879

Miclea, M., Miclea, Ş., \& Ciuca, A. M. (2008). Computer-supported psychotherapy should pay attention to e-learning. Cognitie, Creier, Comportament/Cognition, Brain, Behavior, 12(1), 131.

Miclea, M., Miclea, Ş., Ciuca, A. M., \& Budau, O. (2010). Computer-mediated psychotherapy. Present and prospects. A developer perspective. Cognition, Brain, Behavior: An Interdisciplinary Journal, 14, 185-208.

Mundt, J. C., Marks, I. M., Shear, M. K., \& Greist, J. H. (2002). The Work and Social Adjustment Scale: a simple measure of impairment in functioning. British Journal of Psychiatry, 180, 461-464. doi: DOI 10.1192/bjp.180.5.461

Nordgreen, T., Standal, B., Mannes, H., Haug, T., Sivertsen, B., Carlbring, P., . . . Havik, O. E. (2010). Guided self-help via internet for panic disorder: Dissemination across countries. Comput. Hum. Behav., 26(4), 592-596. doi: 10.1016/j.chb.2009.12.011

Ooi, Y. P., Raja, M., Sung, S. C., Fung, D. S., \& Koh, J. B. (2012). Application of a web-based cognitive-behavioural therapy programme for the treatment of selective mutism in Singapore: a case series study. Singapore Med J, 53(7), 446-450.

Patel, S. R., LaLima, C., Schmidt, A. B. (2015). Implementing internet-based cognitive behavioral therapy for obsessive compulsive disorder: A case report. Annals of Psychiatry and Mental Health, 3(3).

Prochaska, J. O., Norcross, J. C., \& DiClemente, C. C. (2013). Applying the stages of change. Psychotherapy in Australia, 19(2), 10-15.

Richards, D., \& Richardson, T. (2012). Computer-based psychological treatments for depression: A systematic review and meta-analysis. Clinical Psychology Review, 32(4), 329-342. doi: DOI 10.1016/j.cpr.2012.02.004

Richards, J. C., Klein, B., \& Austin, D. W. (2006). Internet cognitive behavioural therapy for panic disorder: does the inclusion of stress management information improve end-state functioning? Clin Psychol, 10. doi: 10.1080/13284200500378795

Rozental, A., Forsström, D., Tangen, J. A., \& Carlbring, P. (2015). Experiences of undergoing Internet-based cognitive behavior therapy for procrastination: A qualitative study. Internet Interventions. doi: 10.1016/j.invent.2015.05.001 
Ruwaard, J., Broeksteeg, J., Schrieken, B., Emmelkamp, P., \& Lange, A. (2010). Web-based therapist-assisted cognitive behavioral treatment of panic symptoms: a randomized controlled trial with a three-year follow-up. Journal of Anxiety Disorders, 24(4), 387396.

Sanchez-Meca, J., Rosa-Alcazar, A. I., Marin-Martinez, F., \& Gomez-Conesa, A. (2010). Psychological treatment of panic disorder with or without agoraphobia: a meta-analysis. Clinical Psychology Review, 30(1), 37-50. doi: 10.1016/j.cpr.2009.08.011

Schmidt, N. B., Lerew, D. R., \& Trakowski, J. H. (1997). Body vigilance in panic disorder: Evaluating attention to bodily perturbations. Journal of Consulting and Clinical Psychology, 65(2), 214-220. doi: Doi 10.1037/0022-006x.65.2.214

Shandley, K., Austin, D. W., Klein, B., Pier, C., Schattner, P., Pierce, D., \& Wade, V. (2008). Therapist-assisted, Internet-based treatment for panic disorder: can general practitioners achieve comparable patient outcomes to psychologists? J Med Internet Res, 10(2).

Sherbourne, C. D., \& Stewart, A. L. (1991). The Mos Social Support Survey. Social Science \& Medicine, 32(6), 705-714. doi: Doi 10.1016/0277-9536(91)90150-B

Simpson, S. G., \& Reid, C. L. (2014). Therapeutic alliance in videoconferencing psychotherapy: a review. Aust J Rural Health, 22(6), 280-299. doi: 10.1111/ajr.12149

Spence, S. H., Donovan, C. L., March, S., Gamble, A., Anderson, R., Prosser, S., . . Kenardy, J. (2008). Online CBT in the Treatment of Child and Adolescent Anxiety Disorders: Issues in the Development of BRAVE-ONLINE and Two Case Illustrations. Behavioural and Cognitive Psychotherapy, 36(Special Issue 04), 411-430. doi: doi:10.1017/S135246580800444X

Titov, N., Andrews, G., Johnston, L., Robinson, E., \& Spence, J. (2010). Transdiagnostic Internet treatment for anxiety disorders: A randomized controlled trial. Behav Res Ther, 48(9), 890-899. doi: DOI 10.1016/j.brat.2010.05.014

Wang, P. S., Berglund, P., Olfson, M., Pincus, H. A., Wells, K. B., \& Kessler, R. C. (2005). Failure and delay in initial treatment contact after first onset of mental disorders in the national comorbidity survey replication. Arch Gen Psychiatry, 62(6), 603-613. doi: DOI 10.1001/archpsyc.62.6.603

Wims, E., Titov, N., Andrews, G., \& Choi, I. (2010). Clinician-assisted Internet-based treatment is effective for panic: A randomized controlled trial. Australian and New Zealand Journal of Psychiatry, 44(7), 599-607.

Zimmerman, M., \& Mattia, J. I. (2001). The Psychiatric Diagnostic Screening Questionnaire: Development, reliability and validity. Comprehensive Psychiatry, 42(3), 175-189. doi: DOI 10.1053/comp.2001.23126 
Maria and Andrea: Comparing Positive and Negative Outcome Cases in an Online,

Clinician-Guided, Self-Help Intervention for Panic Disorder

A.M. Ciuca, T. Berger, \& M. Miclea

Pragmatic Case Studies in Psychotherapy, http://pcsp.libraries.rutgers.edu/

Volume 13, Module 3, Article 1, pp. 173-216, 11-11-17 [copyright by authors]

\section{Table 1. Paxonline Panic Disorder Treatment}

Modules

Introductory module. Anxiety, from normality to pathology

Module 1. Understand what's happening with you

Module 2. Understand what you have to do

Module 3. Reduce hyperactivation through

breathing retraining

Modules 4 and 5. Reduce hyperactivation through autogenic training

Module 6. Reduce hyperactivation through physical exercises

Module 7. Optimizing attentional functioning

Module 8. Changing maladaptive conscious cognitions

Module 9. Changing maladaptive unconscious cognitions

Module 10. Avoidance reduction through
interoceptive exposure

Module 11. Avoidance reduction through exteroceptive exposure

Module 13. Positive emotions development

Module 14. Relapse prevention

Module 12. You learn how to solve problems (optional)

Module 15. Reducing depressive symptoms associated with panic - behavioral activation (optional)

Module 16. Reducing depressive symptoms associated with panic - cognitive restructuring (optional)

\section{Short description}

Psychoeducation concerning fear, anxiety, fight or flight response, the brain circuits involved in the fear response, etiology of anxiety and treatment directions. Normalizes patients' reactions and sets correct expectancies.

Introductory information on panic attacks, panic symptoms and how panic disorder develops. Study cases and video illustrations. Patients begin to register PD related behaviors and thoughts using online worksheets.

Introducing treatment strategies, the treatment plan and boosting confidence and motivation for change.

Information on the effects of hyperventilation, breathing regulation and abdominal breathing exercises.

Inducing relaxation by using autogenic training exercises. Videos and audio files are provided for practice.

Psychological and biological benefits of physical exercises are presented; how to use them regularly.

Attention biases in anxiety and panic disorder. Retraining attention away from the body and panic-like thoughts.

The importance of catastrophic thoughts and attitudes.|

ICAR technique for cognitive restructuring:

*** Identify catastrophic cognitions

*** Challenge each dysfunctional cognition

*** Find the Alternative cognition

${ }^{\star * *}$ Repeat the procedure

Cognitive restructuring techniques for unconscious beliefs. Identify personal values and live by them.

Explain the mechanism of avoidance and prepare for exposure exercises. Reduce fear of bodily sensations through interoceptive exposure.

Reduce avoidance behaviors through gradual exposure to feared situations.

Increase positive emotions in daily life through cognitive and behavioral exercises drawn from positive psychology practices.

Resume the intervention strategies, set the correct expectancies and make a plan to continue improvement and deal with relapse situations.

Learn to organize problems according to importance and urgency. Implement problem-solving technique.

Depression symptoms co-morbid to panic disorder. Behavioral activation techniques.

ICAR technique for cognitive restructuring of dysfunctional cognitions that induce and maintain depression. 
Maria and Andrea: Comparing Positive and Negative Outcome Cases in an Online,

Clinician-Guided, Self-Help Intervention for Panic Disorder

A.M. Ciuca, T. Berger, \& M. Miclea

Pragmatic Case Studies in Psychotherapy, http://pcsp.libraries.rutgers.edu/

Volume 13, Module 3, Article 1, pp. 173-216, 11-11-17 [copyright by authors]

Table 2. Pre and Post-Treatment Scores on Primary and Secondary Outcome Measures

\begin{tabular}{|c|c|c|c|c|c|c|}
\hline & \multicolumn{2}{|c|}{ Maria } & \multicolumn{2}{|c|}{ Andrea } & \multirow[b]{2}{*}{ Range } & \multirow{2}{*}{$\begin{array}{c}\text { Clinical } \\
\text { Scale } \\
\text { Cut-Off } \\
\text { Point }\end{array}$} \\
\hline & $\begin{array}{l}\text { Pre - } \\
\text { treatment }\end{array}$ & $\begin{array}{l}\text { Post - } \\
\text { treatment }\end{array}$ & $\begin{array}{l}\text { Pre - } \\
\text { treatment }\end{array}$ & $\begin{array}{l}\text { Post - } \\
\text { treatment }\end{array}$ & & \\
\hline $\begin{array}{l}\text { Panic Disorder } \\
\text { Severity Scale-Self } \\
\text { Report (PDSS-SR) }\end{array}$ & 18 & $3^{a b}$ & 18 & $11^{\mathrm{b}}$ & $0-28$ & 6 \\
\hline $\begin{array}{l}\text { Work and Social } \\
\text { Adjustment Scale } \\
\text { (WSAS) }\end{array}$ & 17 & $0^{\mathrm{a}}$ & 17 & 10 & $0-40$ & 10 \\
\hline $\begin{array}{l}\text { Patient Health } \\
\text { Questionnaire (PHQ-9) }\end{array}$ & 11 & $3^{a}$ & 12 & $5^{a}$ & $0-27$ & 10 \\
\hline $\begin{array}{l}\text { Panic Attack } \\
\text { Cognitions } \\
\text { Questionnaire } \\
\text { (PACQ) }\end{array}$ & 44 & 2 & 48 & 32 & $0-75$ & - \\
\hline $\begin{array}{l}\text { Agoraphobic } \\
\text { Cognitions } \\
\text { Questionnaire (ACQ): } \\
\text { Physical Concerns } \\
\text { Scale }\end{array}$ & 2.9 & $1.1^{\mathrm{a}}$ & 2.1 & 1.71 & $1-5$ & 1.5 \\
\hline $\begin{array}{l}\text { Agoraphobic } \\
\text { Cognitions } \\
\text { Questionnaire (ACQ): } \\
\text { Loss of Control Scale }\end{array}$ & 2 & $1^{\mathrm{a}}$ & 2.7 & 2.86 & $1-5$ & 1.8 \\
\hline $\begin{array}{l}\text { Body Vigilance Scale } \\
\text { (BVS) }\end{array}$ & 11.1 & 2.4 & 9.67 & 6.6 & $0-20$ & - \\
\hline $\begin{array}{l}\text { Body Sensations } \\
\text { Questionnaire (BSQ) }\end{array}$ & 3.5 & $1.6^{\mathrm{a}}$ & 2.8 & 2.71 & $1-5$ & 1.8 \\
\hline $\begin{array}{l}\text { Global Assessment of } \\
\text { Functioning Scale } \\
(\text { GAF)* }\end{array}$ & 50 & 80 & 45 & 65 & $0-100$ & - \\
\hline $\begin{array}{l}\text { Self-Report Level of } \\
\text { Anxiety }\end{array}$ & 10 & 3 & 10 & 6 & $0-10$ & - \\
\hline
\end{tabular}

* All the scales, with the exception of the GAF Scale, are scored so that the lower the score, the healthier the rating.

${ }^{a}$ Below the clinical cut-off.

b Significant change according to Jacobson \& Truax's (1991) Reliable Change Index. 


$$
\begin{aligned}
& \text { Maria: M1 - ANP - M2 - M3 - M4 - SS1 - M4 and M5 - SS2 - SS3 - M7 - SS4 - } \\
& \text { M15 and M16 - SS5 - M8 - SS6 - M9 - SS7 - M10 - SS8 - M11 --- M13 - SS9 - M14 - }
\end{aligned}
$$

\author{
Andrea: ANP - SS1 - M2 - M3 - M4 - SS2 - M1 - SS3 - M6 - M5 - SS4 - M7 - \\ M8 - SS5 - M8, M3, M6 and M2 - SS6 - M7 GAD - M9 - M10 GAD - SS7 - M10 - SS8 - \\ M11 - M13 - SS9 - M14 - M12 - SS10 - M15 and M16 \\ Note. ANP=Introductory Module, Anxiety from Normality to Pathology (see Table 1) \\ M1-M16 = Modules 1-16, as outlined in Table 1. \\ SS = Skype Session \\ GAD - Generalized Anxiety Disorder Module added (see text for Skype Session 6)
}


Maria and Andrea: Comparing Positive and Negative Outcome Cases in an Online,

Clinician-Guided, Self-Help Intervention for Panic Disorder

A.M. Ciuca, T. Berger, \& M. Miclea

Pragmatic Case Studies in Psychotherapy, http://pcsp.libraries.rutgers.edu/

Volume 13, Module 3, Article 1, pp. 173-216, 11-11-17 [copyright by authors]

Table 4. Results on Additional Measures

\begin{tabular}{|c|c|c|c|c|c|}
\hline & \multicolumn{2}{|l|}{ Maria } & \multicolumn{2}{|c|}{ Andrea } & \multirow{2}{*}{$\begin{array}{l}\text { Range } \\
\text { or } \\
\text { Clinical } \\
\text { Cut-Off }\end{array}$} \\
\hline & Time 1 & Time 2 & Time 1 & Time 2 & \\
\hline $\begin{array}{l}\text { Social Support Scale } \\
\text { (SS-5; Sherbourne \& } \\
\text { Stewart, 1991) }\end{array}$ & 25 & 25 & 19 & 15 & $0-25$ \\
\hline $\begin{array}{l}\text { Working Alliance } \\
\text { Inventory, Tasks } \\
\text { (WAl-S; Horvath \& } \\
\text { Greenberg, 1989) }\end{array}$ & 28 & 28 & 25 & 28 & $0-28$ \\
\hline $\begin{array}{l}\text { Working Alliance } \\
\text { inventory, Goals } \\
\text { (WAI-S; Horvath \& } \\
\text { Greenberg, 1989) }\end{array}$ & 28 & 28 & 22 & 28 & $0-28$ \\
\hline $\begin{array}{l}\text { Working Alliance } \\
\text { Inventory, Bond } \\
\text { (WAl-s; Horvath \& } \\
\text { Greenberg, 1989) }\end{array}$ & 22 & 22 & 28 & 28 & $0-28$ \\
\hline $\begin{array}{l}\text { Credibility } \\
\text { Questionnaire } \\
\text { (CEQ; Devilly \& Borovec, } \\
\text { 2000) }\end{array}$ & 27 & 27 & 20 & 24 & $0-27$ \\
\hline $\begin{array}{l}\text { Expectancy } \\
\text { Questionnaire } \\
\text { (CEQ; Devilley \& Borovec, } \\
\text { 2000) }\end{array}$ & 22 & 24 & 19 & 25 & $0-27$ \\
\hline $\begin{array}{l}\text { Dependent Personality } \\
\text { Subscale* } \\
\text { (OMNI-IV; Loranger, 2001) }\end{array}$ & 60.4 & -- & 71.2 & -- & $\begin{array}{l}\text { Cut-off }= \\
70\end{array}$ \\
\hline $\begin{array}{l}\text { Personal Autonomy } \\
\text { Questionnaire ** } \\
\text { (PAQ; Ciuca, Costache, \& } \\
\text { Albu, in press). }\end{array}$ & 118 & -- & 111 & -- & $\begin{array}{l}\text { Cut-off }= \\
111\end{array}$ \\
\hline $\begin{array}{l}\text { System Usability Scale } \\
\text { (SUS; Lewis \& Sauro, 2009) }\end{array}$ & 97.5 & 100 & 67.5 & 55 & $0-100$ \\
\hline
\end{tabular}

* Higher scores indicate greater dependency.

** Higher scores indicate greater autonomy. 
Maria and Andrea: Comparing Positive and Negative Outcome Cases in an Online,

Clinician-Guided, Self-Help Intervention for Panic Disorder

A.M. Ciuca, T. Berger, \& M. Miclea

Pragmatic Case Studies in Psychotherapy, http://pcsp. libraries.rutgers.edu/

Volume 13, Module 3, Article 1, pp. 173-216, 11-11-17 [copyright by authors]

Figure 1. Maria’s Panic-Attacks-Frequency Monitoring Sheet

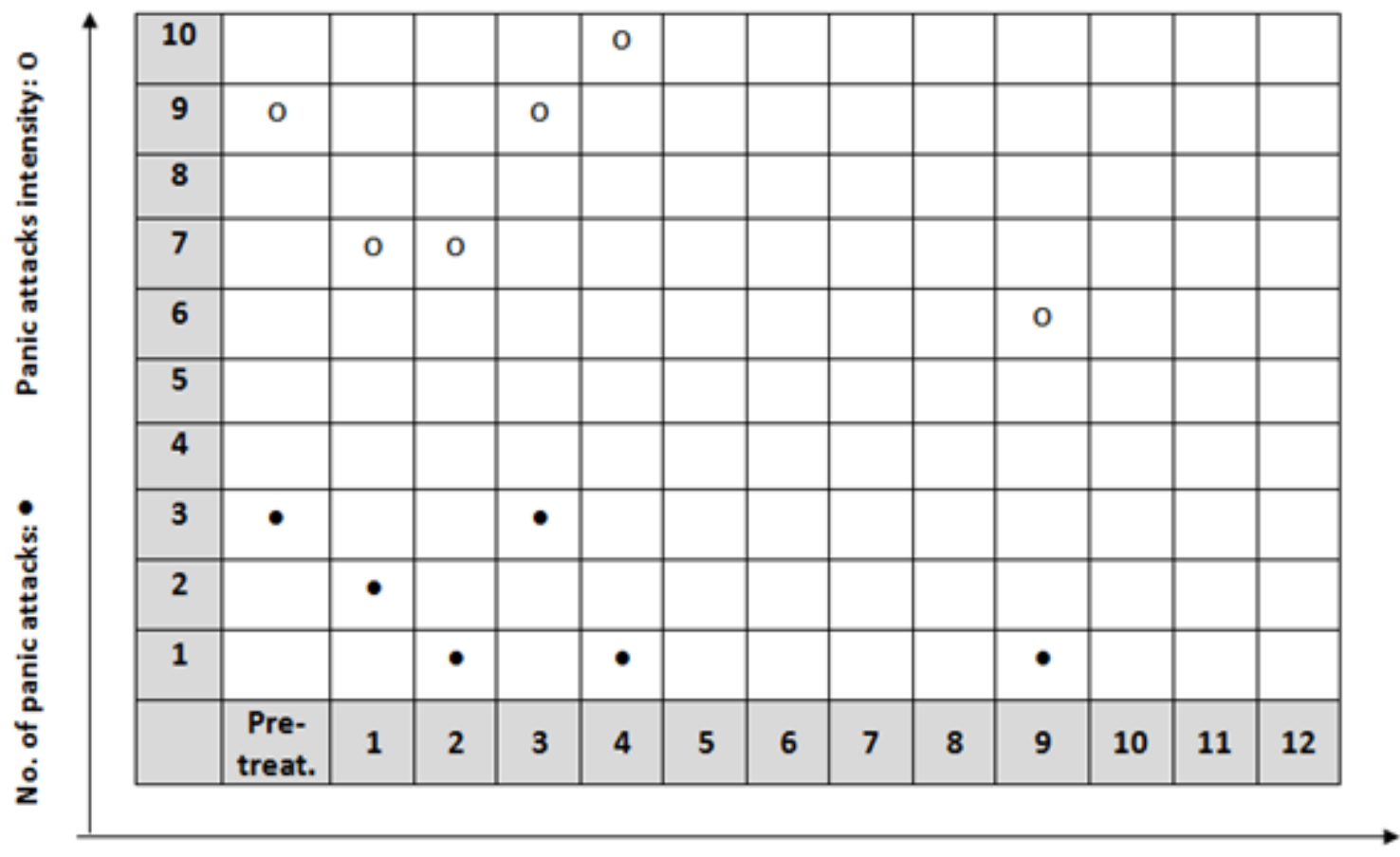

Weeks number

Figure 2. Andrea's Panic-Attacks-Frequency Monitoring Sheet

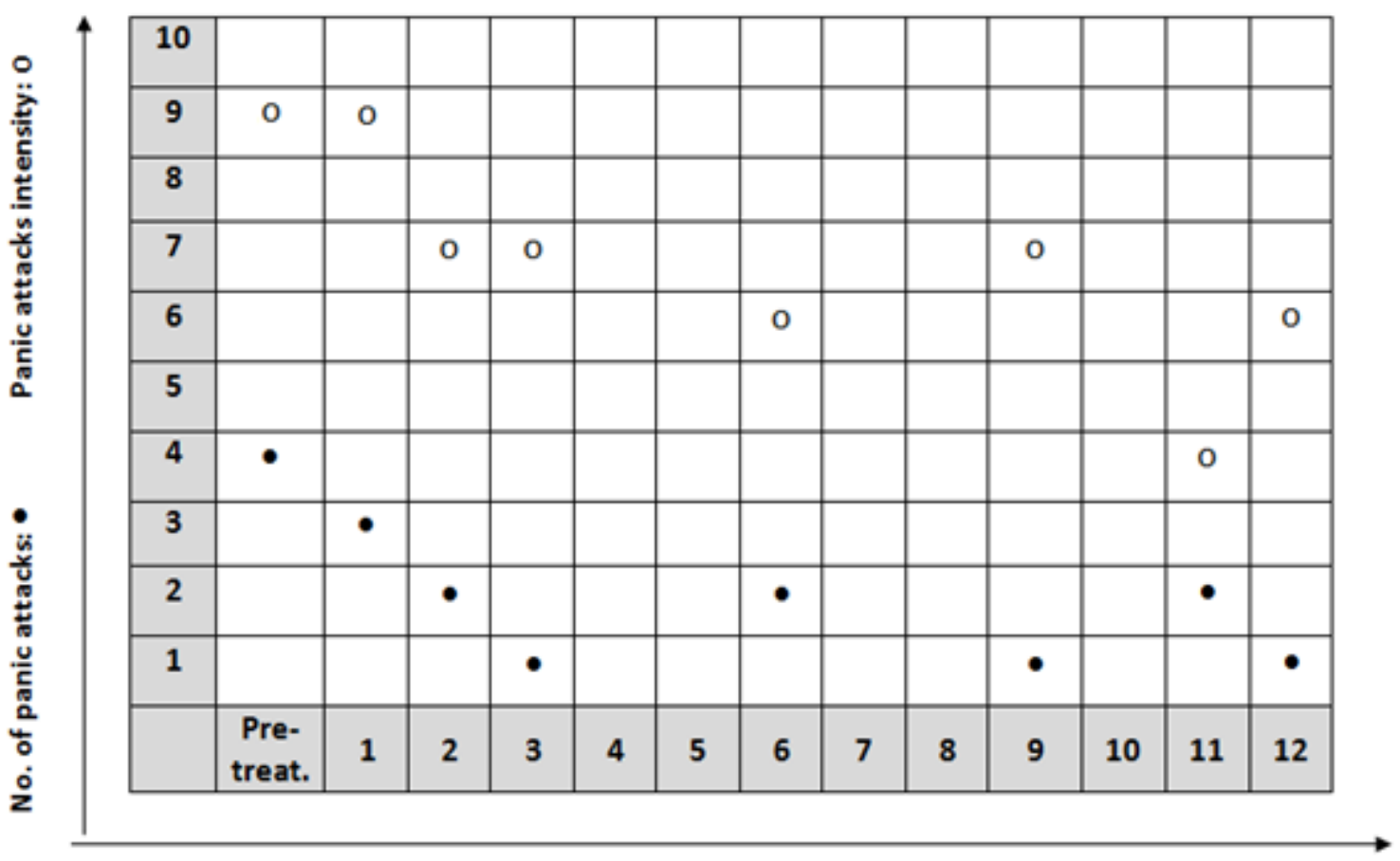

Weeks number 
Maria and Andrea: Comparing Positive and Negative Outcome Cases in an Online,

Clinician-Guided, Self-Help Intervention for Panic Disorder

A.M. Ciuca, T. Berger, \& M. Miclea

Pragmatic Case Studies in Psychotherapy, http://pcsp.libraries.rutgers.edu/

Volume 13, Module 3, Article 1, pp. 173-216, 11-11-17 [copyright by authors]

Figure 3. Maria’s Mood Tracker, Before and After Each Module

\section{My mood tracker}

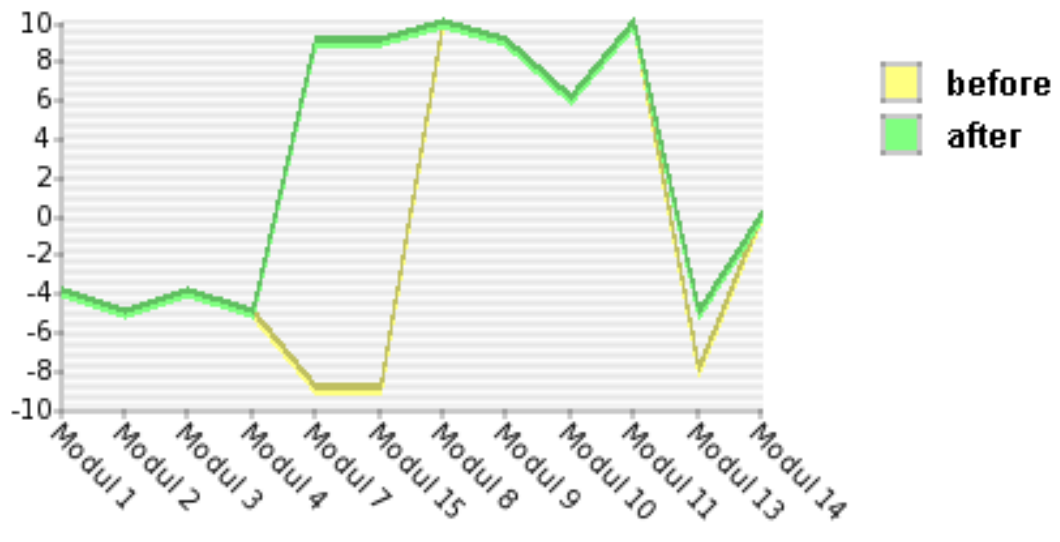

Figure 4. Maria’s Anxiety Tracker, Before and After Each Module

My anxiety tracker

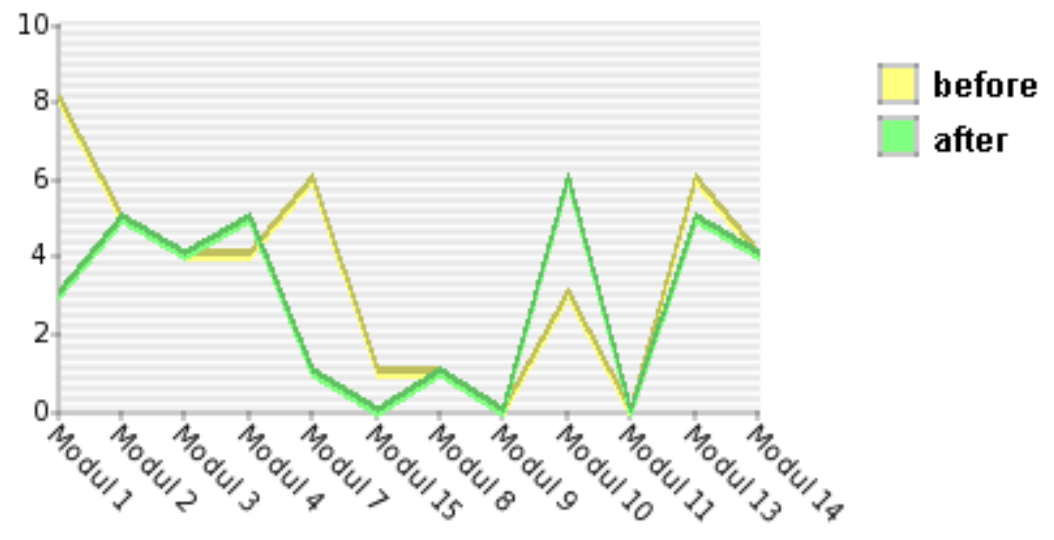


Maria and Andrea: Comparing Positive and Negative Outcome Cases in an Online,

Clinician-Guided, Self-Help Intervention for Panic Disorder

A.M. Ciuca, T. Berger, \& M. Miclea

Pragmatic Case Studies in Psychotherapy, http://pcsp.libraries.rutgers.edu/

Volume 13, Module 3, Article 1, pp. 173-216, 11-11-17 [copyright by authors]

Figure 5. Andrea's Mood Tracker, Before and After Each Module

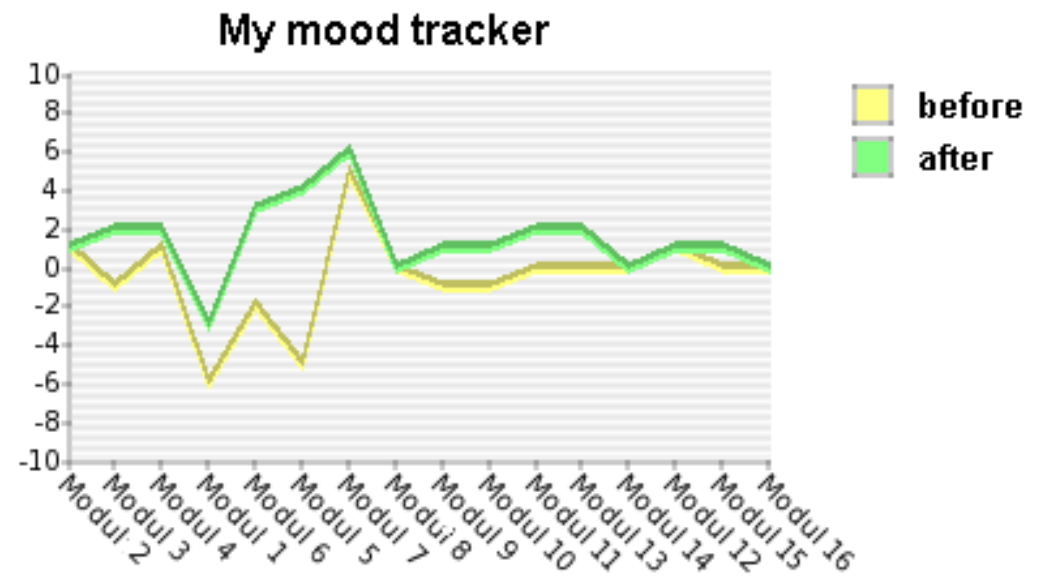

Figure 6. Andrea’s Anxiety Tracker For Andrea, Before And After Each Module

My anxiety tracker

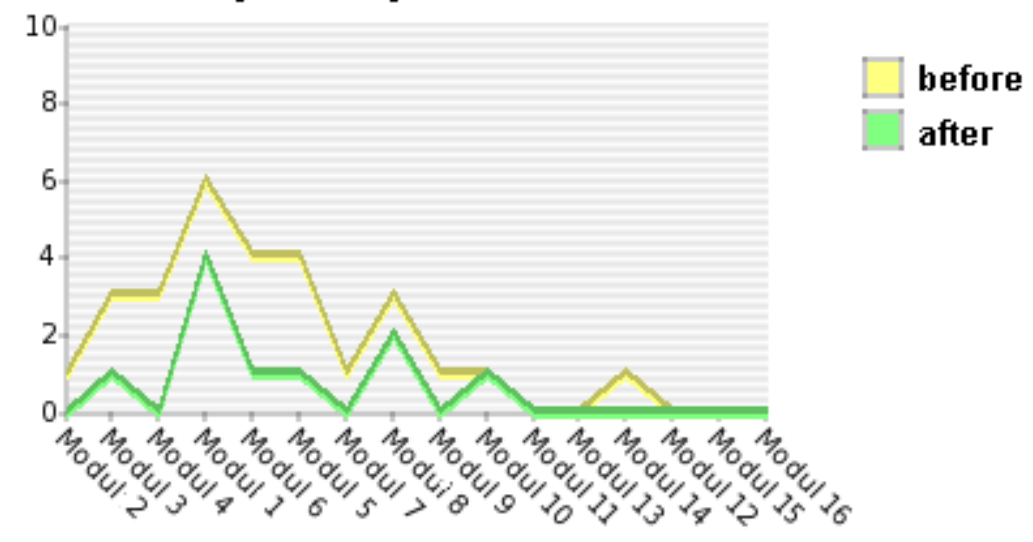

